\title{
Narrative review of vascular iatrogenic trauma and endovascular treatment
}

\author{
Tyler Andrew Smith ${ }^{1}$, David Gage ${ }^{2}$, Keith Bertram Quencer ${ }^{1}$ \\ ${ }^{1}$ Department of Interventional Radiology, University of Utah, Salt Lake City, UT, USA; ${ }^{2}$ Department of Medicine, Intermountain Healthcare, \\ Murray, UT, USA \\ Contributions: (I) Conception and design: All authors; (II) Administrative support: KB Quencer; (III) Provision of study materials or patients: All \\ authors; (IV) Collection and assembly of data: All authors; (V) Data analysis and interpretation: All authors; (VI) Manuscript writing: All authors; (VII) \\ Final approval of manuscript: All authors. \\ Correspondence to: Tyler Andrew Smith. Department of Interventional Radiology, University of Utah, 30 N 1900 E, Salt Lake City, UT 84132 , USA. \\ Email: Tyler.a.smith@hsc.utah.edu.
}

\begin{abstract}
Iatrogenic injury is unfortunately a leading cause of morbidity and mortality for patients worldwide. The etiology of iatrogenic injury is broad, and can be seen with both diagnostic and therapeutic interventions. While steps can be taken to reduce the occurrence of iatrogenic injury, it is often not completely avoidable. Once iatrogenic injury has occurred, prompt recognition and appropriate management can help reduce further harm. The objective of this narrative review it to help reader better understand the risk factors associated with, and treatment options for a broad range of potential iatrogenic injuries by presenting a series of iatrogenic injury cases. This review also discusses rates, risk factors, as well as imaging and clinical signs of iatrogenic injury with an emphasis on endovascular and minimally invasive treatments. While iatrogenic vascular injury once required surgical intervention, now minimally invasive endovascular treatment is a potential option for certain patients. Further research is needed to help identify patients that are at the highest risk for iatrogenic injury, allowing patients and providers to reconsider or avoid interventions where the risk of iatrogenic injury may outweigh the benefit. Further research is also needed to better define outcomes for patients with iatrogenic vascular injury treated with minimally invasive endovascular techniques verses conservative management or surgical intervention.
\end{abstract}

Keywords: Iatrogenic injury; embolization; adverse event

Submitted May 29, 2020. Accepted for publication Aug 12, 2020.

doi: $10.21037 /$ atm-20-4332

View this article at: http://dx.doi.org/10.21037/atm-20-4332

\section{Introduction}

Although the words "primum non nocere" (Latin for first do no harm) are often misattributed to Hippocratic oath, it nonetheless remains a guiding principle for physicians of every specialty. While avoidance of any harm to patients is impossible, interventions which provide a net benefit to patients are frequently undertaken. No treatment is without risk, however harm caused by medical therapy is the exception rather than an expected outcome. The objective of this narrative review is to help the reader better understand the risk factors of iatrogenic injury, clinical and imaging findings, and potential treatment options with a focus on endovascular and minimally invasive treatments.

We present the following article in accordance with the Narrative Review reporting checklist (available at http:// dx.doi.org/10.21037/atm-20-4332).

\section{Methods}

A literature search was conducted using PubMed (US National Library of Medicine, Bethesda, MD, USA). No studies were excluded based on year of publication. Studies which investigated risk factors, rates, clinical signs, 

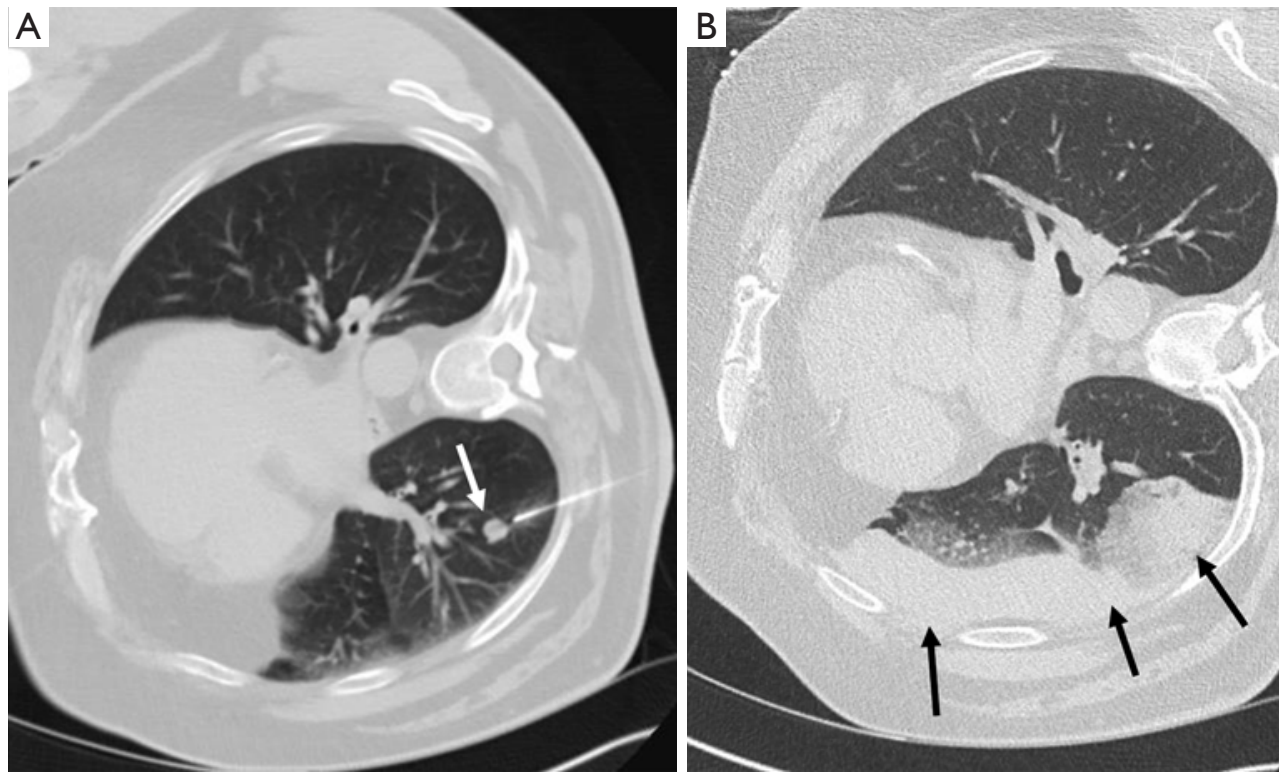

Figure 1 A 67-year-old male with metastatic melanoma and multiple new pulmonary nodules measuring up to $1.2 \mathrm{~cm}$. Biopsy of one of the pulmonary nodules was requested (A, white arrow). The biopsy was complicated by prompt development of pulmonary hemorrhage (black arrows).

imaging findings, and management of iatrogenic injury were included, with an emphasis on minimally invasive and endovascular management.

\section{Chest}

\section{Lung biopsy}

Lung cancer is the most common cause of cancer related deaths worldwide (1). Percutaneous biopsy allows for diagnosis and targeted therapy but is not without risk (Figure 1). Despite its utility, complications do occur at a relatively high frequency, with an overall complication rate of $38.8 \%$ for CT-guided core biopsy (2). The most common complication is pneumothorax, occurring in approximately $25 \%$ of biopsies (2) (Figure 2). Hemoptysis occurs in between $1.7 \%$ and $4.1 \%$ of patients (2). Other rare complications include air embolism and tumor seeding (3).

Risk factors for pneumothorax include emphysema, long needle pass, smaller lesions, fissure puncture, multiple needle passes across the pleura (4). Risk factors for significant pulmonary hemorrhage include deep location, older age, female sex, and emphysema (5). The initial treatment for pneumothorax is supplemental oxygen; a chest tube is indicated if the pneumothorax is symptomatic, growing, or pneumothoraxes with $>35 \mathrm{~mm}$ of pleural separation (6).

\section{Swan-Ganz catheter placement}

In patients with difficult to manage cardiogenic shock, pulmonary artery catheterization may be indicated to help with titration of pressor medications and fluid administration (7). Major and minor complications associated with pulmonary arterial catheter placement occur in $4.4 \%$ and $23 \%$ of cases respectfully (8). Complications can include inadvertent arterial puncture (approximately $1.9 \%$ of cases), pneumothorax $(0.5 \%$ of cases), catheter induced thrombosis (1.9-22\% of cases, depending on site of vascular access), cardiac arrhythmias $(12.5-70 \%)$, damage to cardiac valves or chordae $(0.9 \%)$, and rarely pulmonary arterial rupture or perforation $(0.03-0.20 \%)$ (9). Case reports have described ventricular perforation as a potential complication (10). Unfortunately rupture of the pulmonary artery is associated with an overall mortality rate of $53-70 \%$ (8). Potential treatment options include surgery or minimally invasive endovascular procedures (8). A small series of 6 patients who developed traumatic pulmonary artery pseudoaneurysms following swan-ganz catheter placement treated with coils, absorbable gelatin embolics (gelfoam) had a technical success rate of $100 \%$, with no patient developing recurrent 

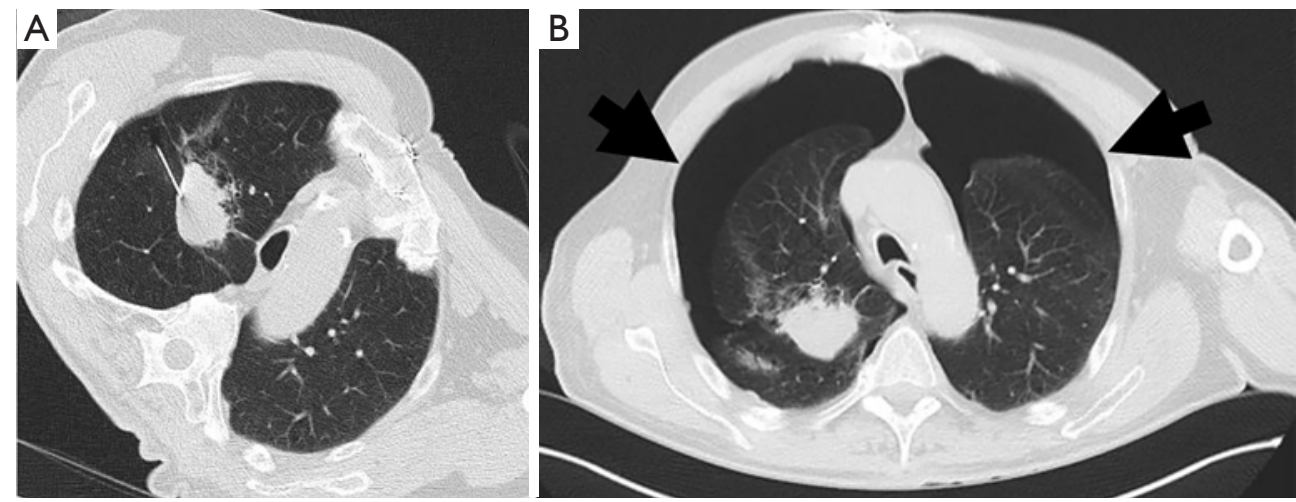

Figure 2 A 70-year-old female with an enlarging lung mass. (A) The patient underwent CT needle guided biopsy. (B) The biopsy was complicated by bilateral pneumothoraces (black arrows), known as a buffalo pneumothorax. The patient was treated with a chest tube and required hospitalization for several days before the chest tube could be removed. Bilateral pneumothoraces can be present in patients with incomplete pleural fusion.

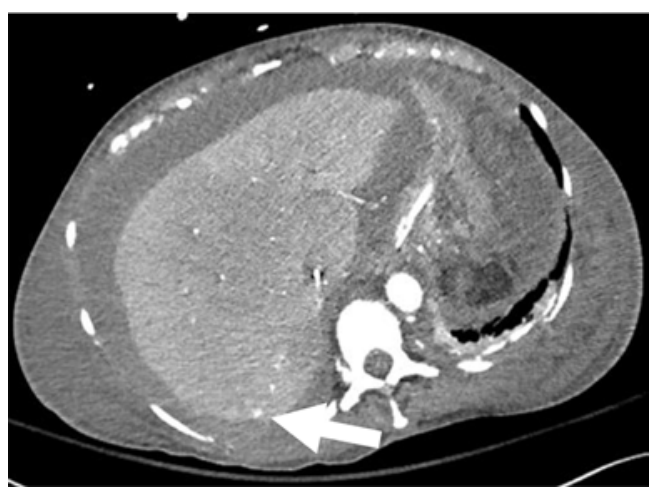

Figure 3 A 71-year-old female with a history of myelofibrosis status post unsuccessful right sided thoracentesis without US guidance which was complicated hypotension and hemoperitoneum. CTA demonstrated focal extravasation from the right lobe of the liver with high density clot (white arrow). Patient subsequently expired of complications of acute blood loss anemia.

hemoptysis and 4 of 6 patients eventually being discharged from the hospital (11).

\section{Chest tube}

Chest tube placement, also known as thoracostomy tube, is a commonly performed procedure for the treatment of pleural space disease including pneumothorax, empyema, pleural effusions, and trauma. Reported complication rates from thoracostomy tube placement are highly variable, ranging from $1-40 \%$, however a recent meta-analysis of 29 papers and 949 patients found a complication rate of $19 \%$ (12).
Complications associated with thoracostomy tubes can broadly be described as insertional (injuries caused at the time of placement, 14.4-15.3\%), positional (malfunction of the tube or damage to structures following a successful placement, 53.1-68.9\%), removal (new or persistent pneumothorax, or bleeding $16.2-16.7 \%)$, or infection (0$14.8 \%)(12,13)$.

\section{Thoracentesis}

It is estimated that approximately one hundred and seventyeight thousand thoracenteses are performed annually (14). Common complications include hemorrhage (hemothorax and chest wall hematoma), pneumothorax, and re-expansion pulmonary edema (15) (Figure 3). A cohort study examining over 9,300 thoracenteses found rates of hemorrhage at $0.18 \%$, pneumothorax $0.61 \%$, and re-expansion pulmonary edema at $0.01 \%(16)$. Hemorrhage is a rare complication of thoracentesis with an incidence rate from $0.12-2 \%$ and often due to laceration of an intercostal artery (ICA) or an associated branch (Figure 4). Cadaveric studies show increased tortuosity of the ICA within $6 \mathrm{~cm}$ of midline, in patients older than 60, and in more cephalad rib spaces (17). Physician-performed US was found to be $86 \%$ sensitive for identifying the ICA with median time to locate the vessel of 42 seconds for portable US and 18 seconds for high-end US (18). One study including $>19,000$ thoracenteses showed that US guidance was associated with a $38.7 \%$ reduction in hemorrhage and $16.3 \%$ reduction in pneumothorax (19).

Risk factors for pneumothorax include BMI $<18$, removing $>1,500 \mathrm{~mL}$, and two or more needle passes (16). 

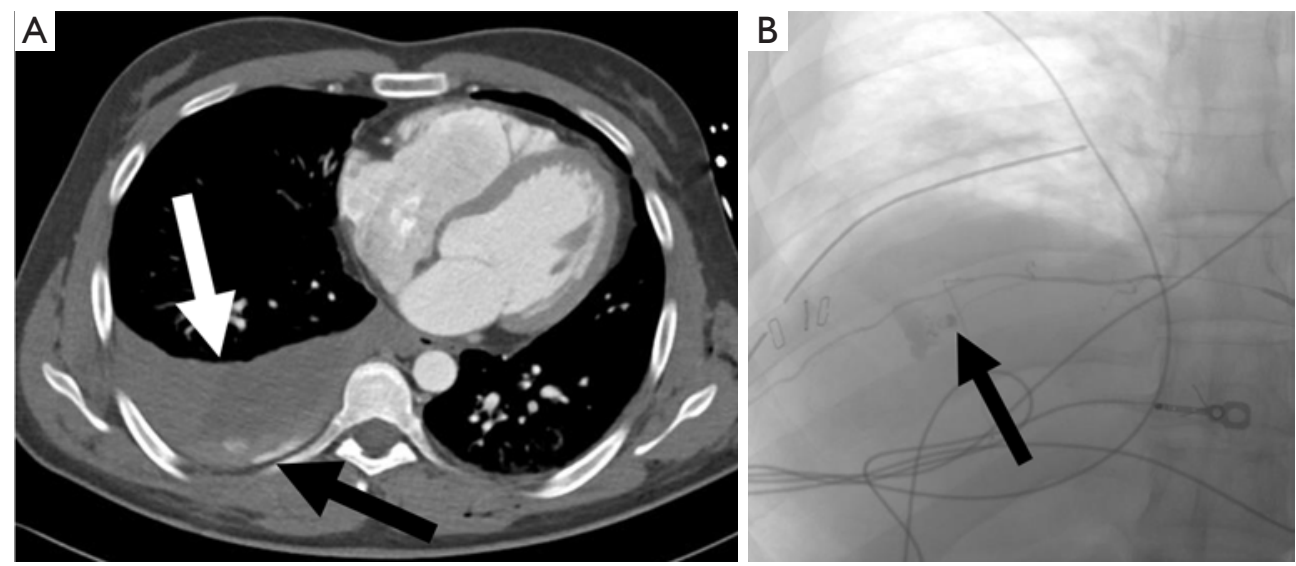

Figure 4 A 55-year-old male, status post thoracentesis. (A) The procedure was complicated by intercostal vascular injury, with contrast pooling adjacent to the ribs, suggestive of active bleeding (black arrow) and the development hemothorax (white arrow). (B) Angiography demonstrated pseudoaneurysm and active extravasation from an intercostal artery (black arrow).

Moderate coagulopathies (considered INR greater than 3 and platelets less than $25,000 / \mathrm{microL}$ ) and mechanical ventilation were not found to increase risk of complications (17).

Risk factors for hemorrhage include renal disease, small pleural effusion, obesity, complicated pleural space, suboptimal patient position, lack of operator experience, lack of ultrasound guidance, and large-volume drainage (15).

\section{Liver}

\section{Percutaneous transhepatic biliary drainage (PTBD)}

PTBD allows for relief of malignant obstruction of the biliary system. There is a high technical success rate of PTBD, ranging from $91.2-100 \%$, with a non-dilated biliary system being a common cause for technical difficulty (20). PTBD has similar therapeutic success rates and overall complication rates when compared to endoscopic biliary dilation. However, meta-analysis found PTBD to be more likely to cause bleeding (OR 1.81) and tube dislocation (OR 3.41). Traumatic complications of PTBD include injury to the hepatic artery or portal vein, bile leak, and duodenal perforation $(21,22)$. Studies of PTBD catheter placements reported an overall complication rate of ranging from 5.2$10.8 \%(20,23)$ (Figure 5).

\section{Liver biopsy}

Liver biopsy is a minimally invasive procedure which allows for further evaluation of liver pathology and is a gold standard in the workup of fibrosis, chronic hepatitis, and liver cancer $(24,25)$. Complications include hemorrhage, which has been reported from $0-10.9 \%$, with most studies reporting rates less than $2 \%(26-28)$.

\section{Transjugular intrabepatic portosystemic shunt (TIPS)}

TIPS treats portal hypertension through the creation of a connection between the portal venous system and hepatic venous system. Technical success rates are high; however, complications can affect patient prognosis and include acute liver failure, hepatic encephalopathy, hemorrhage, biliary injury, thrombosis, and shunt migration or dysfunction (29) (Figure 6). Unfortunately, many patients with portal hypertension and liver disease have elevated INR and low platelets, further increasing the risk of bleeding (29). Internal jugular vein and hepatic vein access should be performed under ultrasound and fluoroscopic guidance to avoid arterial access or right atrial injury (29). Arterial injuries are rare and occur in less than $2 \%$ of TIPS cases (30). If there is an injury to the portal venous system patients can suffer rapid blood loss due to underlying portal hypertension, and if significant injury is suspected portal venography should be performed to identify and treat the source of bleed (29). Portal vein dissections can be treated with the extension of the TIPS stent over the dissection flap (31). Liver capsule transgression occurs in $33 \%$ of TIPS cases, however, hemorrhage related to capsule injury only occurs in 1-2\% of cases (32). Following the procedure liver laceration causing intra-abdominal 

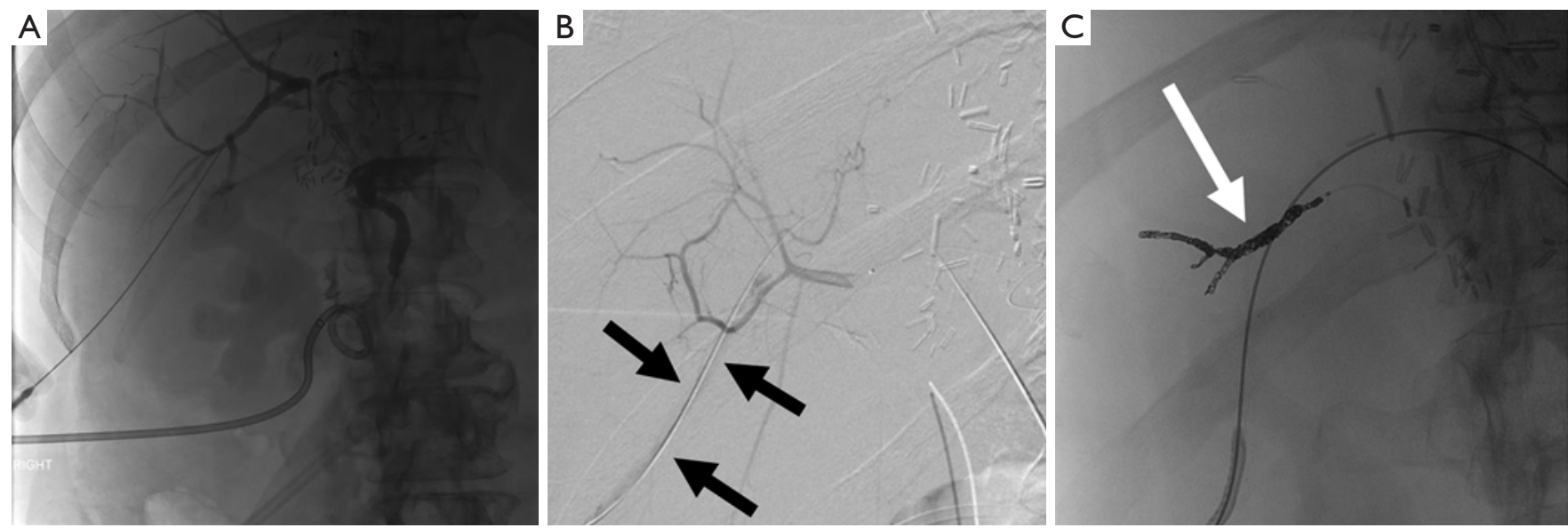

Figure 5 A 51-year-old male with a history of liver transplant and biliary drainage for the treatment of a bile leak. The patient developed significant haemobilia and a drop in hemoglobin, prompting further evaluation. (A) Initial angiogram failed to show the source of bleeding. (B) Once the drain was over a wire removed extravasation from a hepatic artery was seen, with blood leaking into the biliary drain tract (black arrows). (C) This was treated with coil embolization (white arrow).

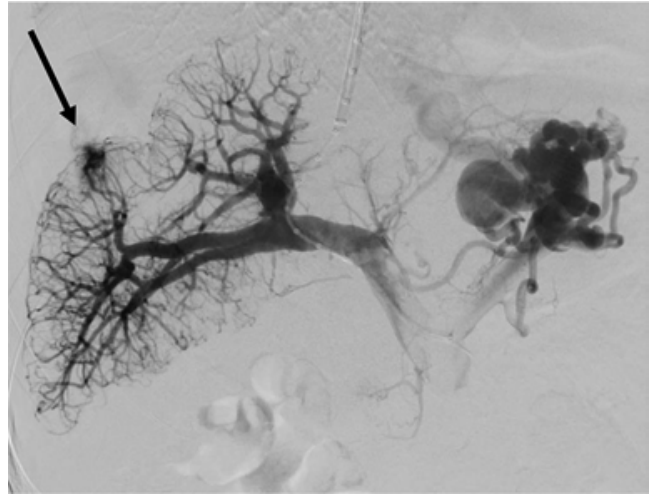

Figure 6 A 58-year-old male with portal hypertension who was undergoing TIPS placement for refractory ascites. Portal venogram demonstrated a brisk capsular bleed (black arrow). Despite best medical management in the ICU and repeated transfusions the patient subsequently expired. TIPS, transjugular intrahepatic portosystemic shunt.

hemorrhage has been reported up to 8 days following TIPS in patients treated with heparin, and case reports have reported hemorrhage up to 2 weeks following the procedure in patients treated with heparin or warfarin $(29,33)$. Patients who are able to tolerate a brief cessation of anticoagulation can avoid the rare but potentially morbid complication (29). Hepatic encephalopathy occurs in $5-35 \%$ of patients following TIPS and can occur days or months after placement, however this complication can be largely avoided with strict adherence to lactulose regimens and protein restricted diets (29). Patients with severe encephalopathy or acute liver following TIPS, stent occlusion should be considered (29).

\section{Transarterial chemoembolization (TACE)}

TACE is commonly performed for the treatment of unresectable hepatocellular carcinoma. Major complications are reported in approximately $5 \%$ of cases, with a risk of death approaching 1\% (34). Arterial access is required for TACE, and although complications related to puncture site is rare, hematoma may develop in up to $2 \%$ of patients and rarely pseudoaneurysm of arteriovenous fistula may develop (34). Hepatic and celiac artery injury including arterial spasm, dissection, or thrombosis are more common and observed in $0.5-2.7 \%$ of cases (35) (Figure 7). Due to the high rates of normal variants in hepatic arterial anatomy, non-target embolization is a potential complication, and can cause significant iatrogenic injury (34). Common sites of nontarget embolization include gastric arteries, gastroduodenal artery, cystic artery, parasitized blood supply from the inferior phrenic artery, and even cutaneous branch embolization such as the superior epigastric artery (34). Arteriovenous shunting or porto-venous shunting can result in pulmonary embolization (34). Following the procedure post embolization syndrome (fever, malaise, right upper 

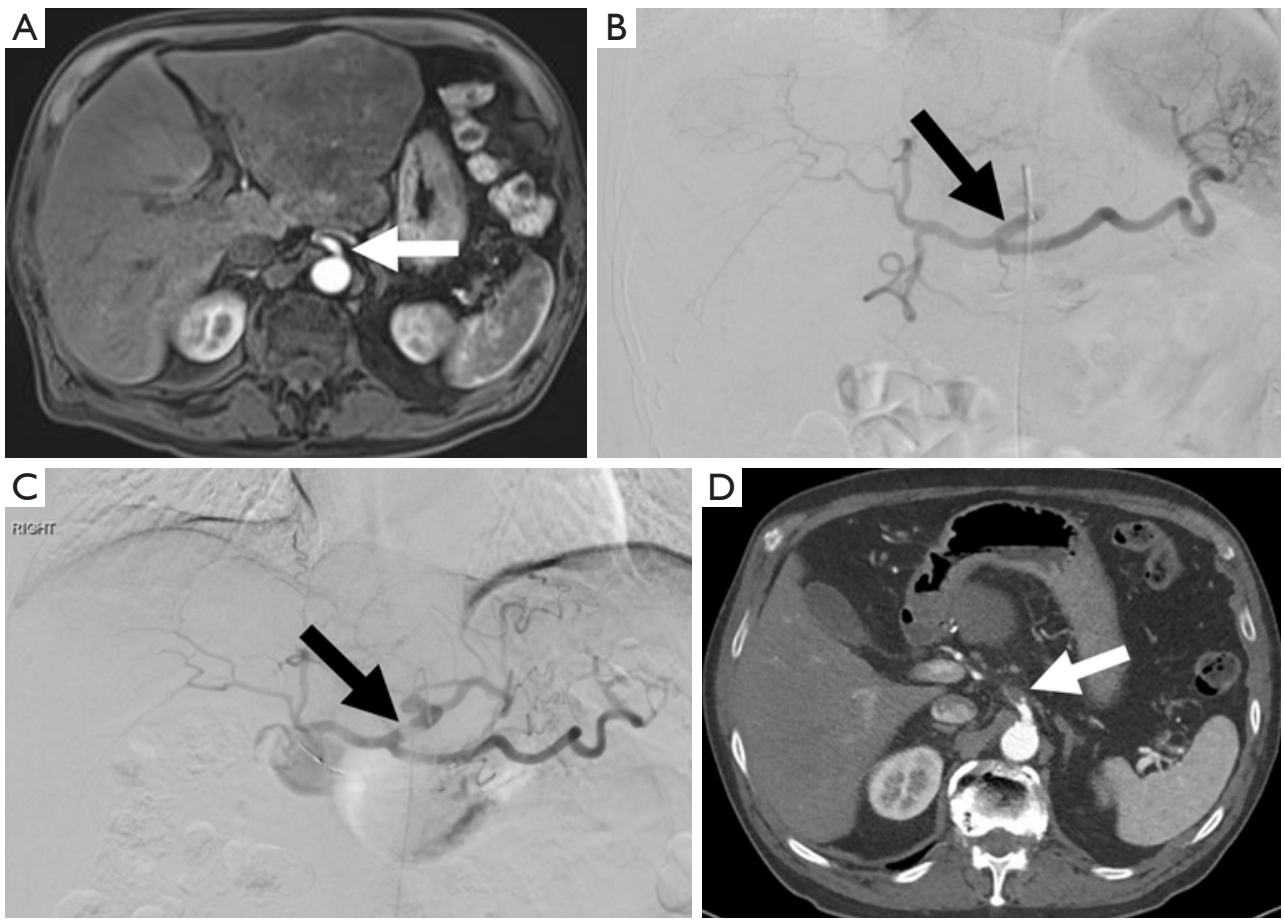

Figure 7 A 75 -year-old male with hepatocellular carcinoma. (A) Initial MRA showed a normal celiac trunk (white arrow). (B) Initial celiac angiograms showed normal vessels, with a normal celiac trunk (black arrow). (C) After catheterization and intervention, hepatic angiogram showed a dissection of the celiac trunk (black arrow). (D) Subsequent CTA demonstrated a flow limiting dissection of the celiac trunk with thrombosis of the false lumen (white arrow). The patient was treated with stent placement, which resumed normal flow to the celiac trunk (not pictured).

quadrant pain, nausea and vomiting) is observed in up to $90 \%$ of patients (34). Infection following TACE can be seen in $2-3 \%$ of patients receiving prophylactic antibiotics, and $11 \%$ of patients without prophylactic antibiotics (36).

\section{Spleen}

Pathologies that involve the spleen are numerous, and include infection, malignancies including lymphoma, leukemia, and melanoma, and systemic diseases. Differentiating splenic pathology can be difficult to diagnose based on imaging characteristics alone, therefore histologic evaluation is often indicated (37). Unfortunately, early reports of core needle splenic biopsy found high rates of major bleeding (38). Subsequent series using fine needle aspiration reported no bleeding complications, but at the expense of limited diagnostic utility $(37,39)$. More recent studies with small sample sizes or using pooled data from both fine needle aspiration and core needle biopsy reported low complication rates (40-43). A 2016 study of 97 patients undergoing core needle biopsy of the spleen reported an overall complication rate of $8.2 \%$, but a major complication rate of $1 \%$ (hemothorax requiring chest tube, transfusions, and embolization of bleeding pseudoaneurysm) (37). Another recent study reviewing 52 cases of core needle splenic biopsy reported a major complication rate of $0 \%$ and a minor complication rate of $1.9 \%$ (44). Given the recent reports of low complication during splenic biopsy, it should not be withheld when pathologic diagnosis is clinically indicated (37).

The spleen can also be injured during therapeutic embolization. Splenic partial embolization is often indicated in patients with hypersplenism and thrombocytopenia, and can avoid risks associated with surgical splenectomy including portal and mesenteric vein thrombosis and post splenectomy infection (45-47) (Figure 8). Although partial splenic embolization has advantages over splenectomy, this procedure is not without risk, and reported complications include post embolization syndrome, pneumonia, atelectasis, or abscess (45). Splenic abscess has a high 

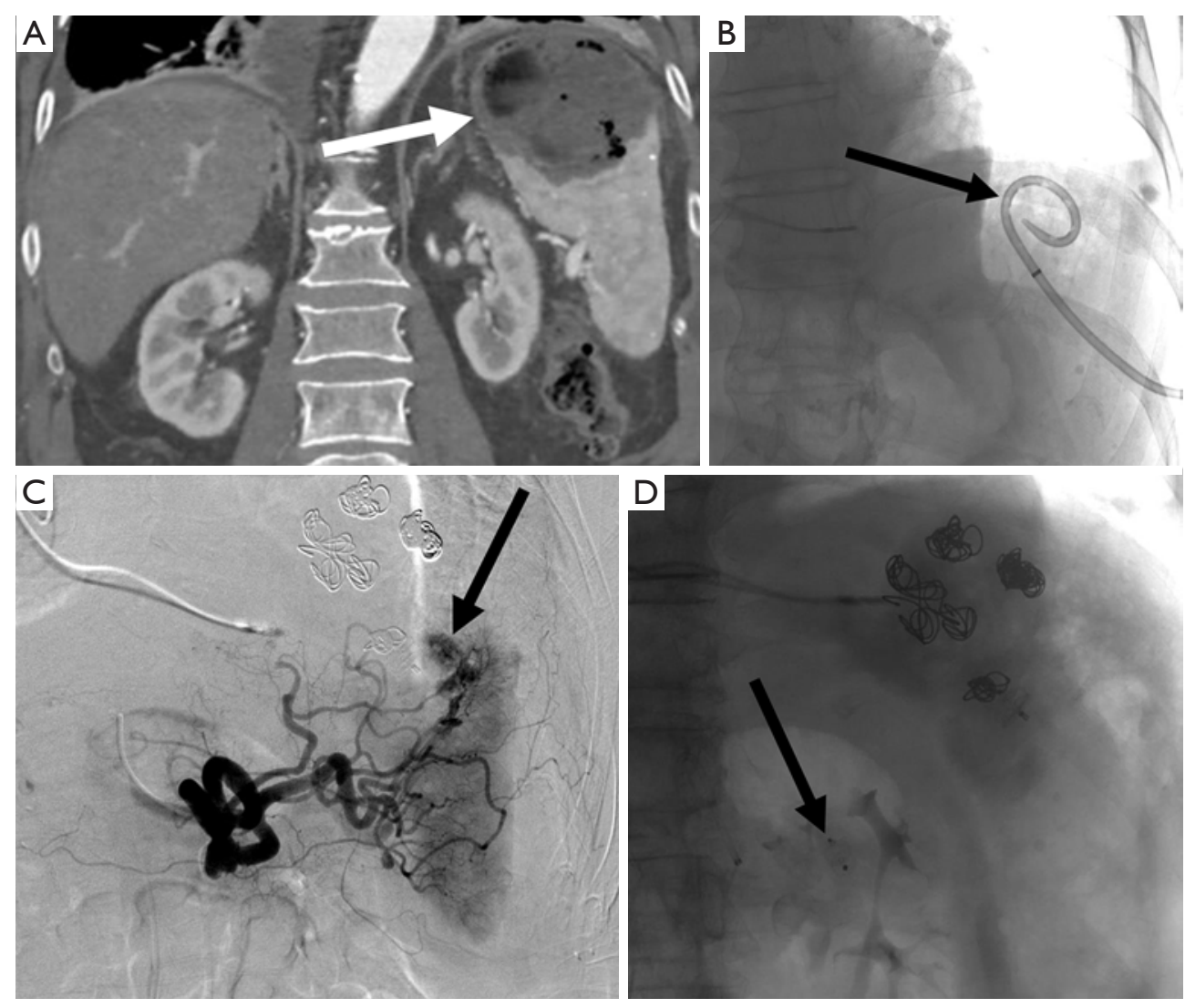

Figure 8 A 88-year-old male with multiple medical problems who presented with fever and abdominal pain following therapeutic splenic embolization for hypersplenism and thrombocytopenia. (A) Contrast enhanced CT was performed and demonstrated a splenic abscess (white arrow). (B) The abscess was initially treated with percutaneous abscess drain (black arrow). After the drainage catheter was removed the patient became hypotensive. Interventional radiology was consulted for splenic artery embolization. (C) Initial splenic artery angiogram demonstrated extravasation of contrast from distal splenic vessels adjacent to the abscess cavity (black arrow). (D) Mid splenic artery embolization was performed (black arrow), and the patient's hemodynamic status improved.

mortality rate (reported up to $16 \%$ ), and occurs in $6.8 \%$ of patients undergoing splenic embolization (48-50). Once splenic abscess is identified, appropriate treatment with antibiotics and surgical or catheter abscess drainage can reduce mortality rate to $5.6 \%(48,51)$. Prophylactic antibiotic therapy is indicated for these patients to reduce risk of infection (48).

\section{Renal}

\section{Renal biopsy}

Percutaneous renal biopsy is a commonly performed procedure to diagnose renal disease, however this procedure is not without risks. The most commonly reported major risk is severe bleeding (52) (Figures 9-11).
One study which included 500 consecutive percutaneous renal biopsies found a major complication rate of $2.4 \%$ and $41.2 \%$ minor complication rate $(53)$. There were no deaths reported in this study, but $1.8 \%$ of patients required blood transfusions, and one patient required endovascular embolization (53). Minor complications included hematoma detected by imaging, drop in hemoglobin greater than or equal to $1 \mathrm{~g} / \mathrm{dL}$, and hematuria (53). Another more recent retrospective study of 644 patients reported major bleeding in $4.3 \%$ of cases (28 total patients). Of these patients, 4 required endovascular embolization and 1 required surgery to control bleeding (52). Interestingly they found the only patient characteristic that was associated with a need for blood transfusion was baseline hemoglobin at the time 

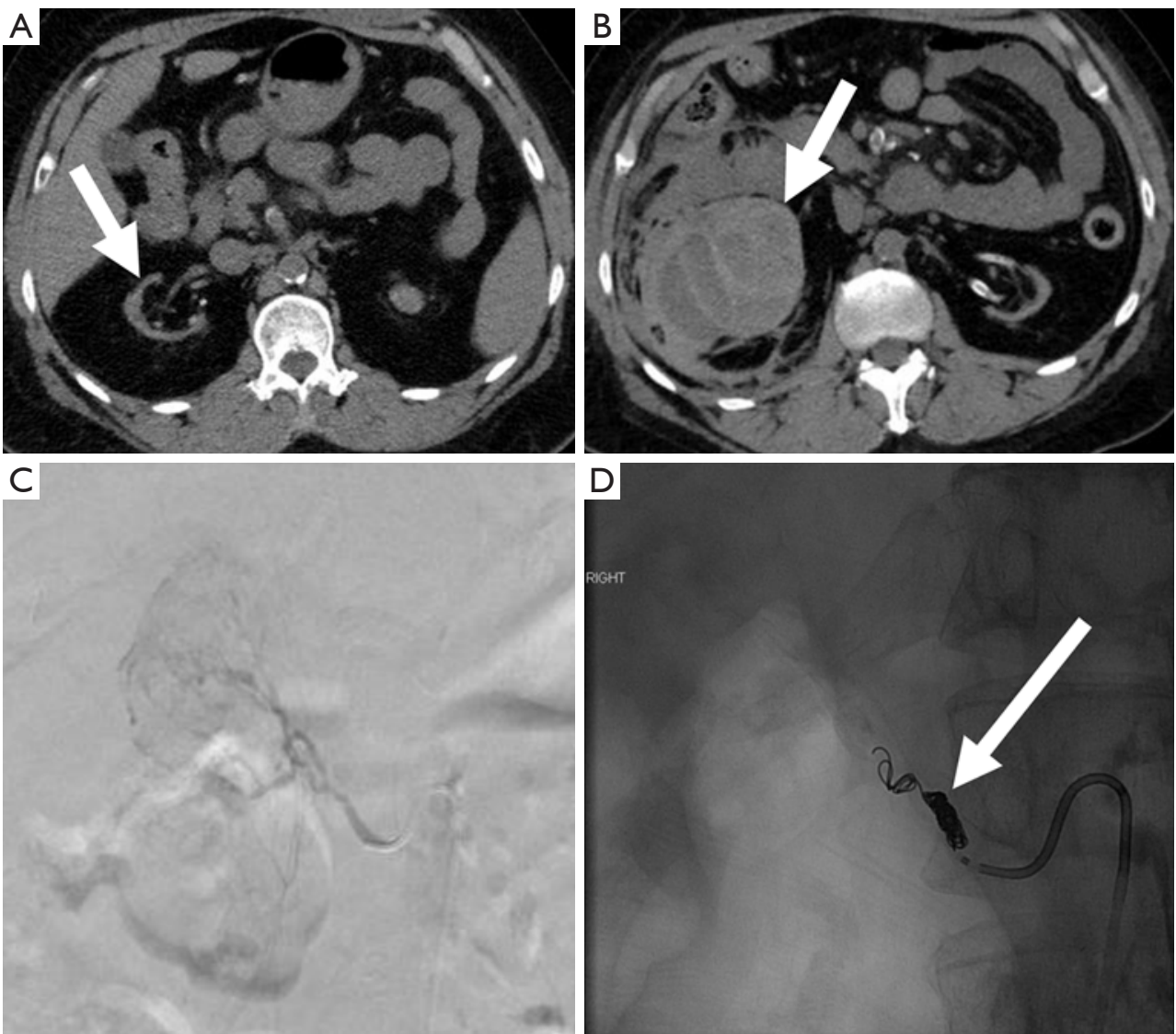

Figure 9 A 51-year-old female status post biopsy of an atrophic right kidney (A, white arrow). Following the biopsy, the patient experienced dropping blood pressure and hypotension. (B) Subsequent non-contrast CT demonstrated a large hematoma in the right retroperitoneum (white arrow). (C) Angiography of the kidney was performed. (D) Since the kidney had minimal function at baseline, the whole kidney was embolized with coils (white arrow).
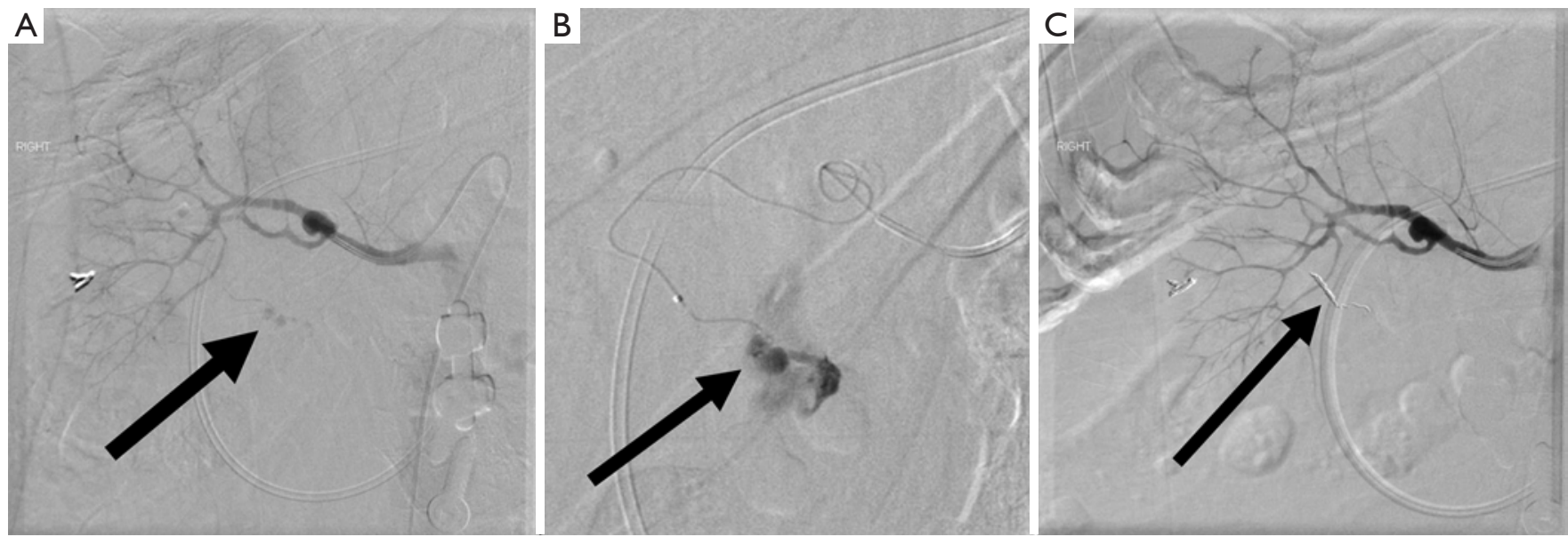

Figure 10 A 77-year-old male with elevated creatinine. Following kidney biopsy, the patient presented with hypotension. (A) The patient was taken urgently to angiography which demonstrated small pseudoaneurysms in the inferior pole (black arrow). (B) Selective angiography demonstrated extravasation of contrast from pseudoaneurysms (black arrow). (C) Coil embolization was performed (black arrow), and post embolization angiography showed complete devascularization of the injured renal artery. 

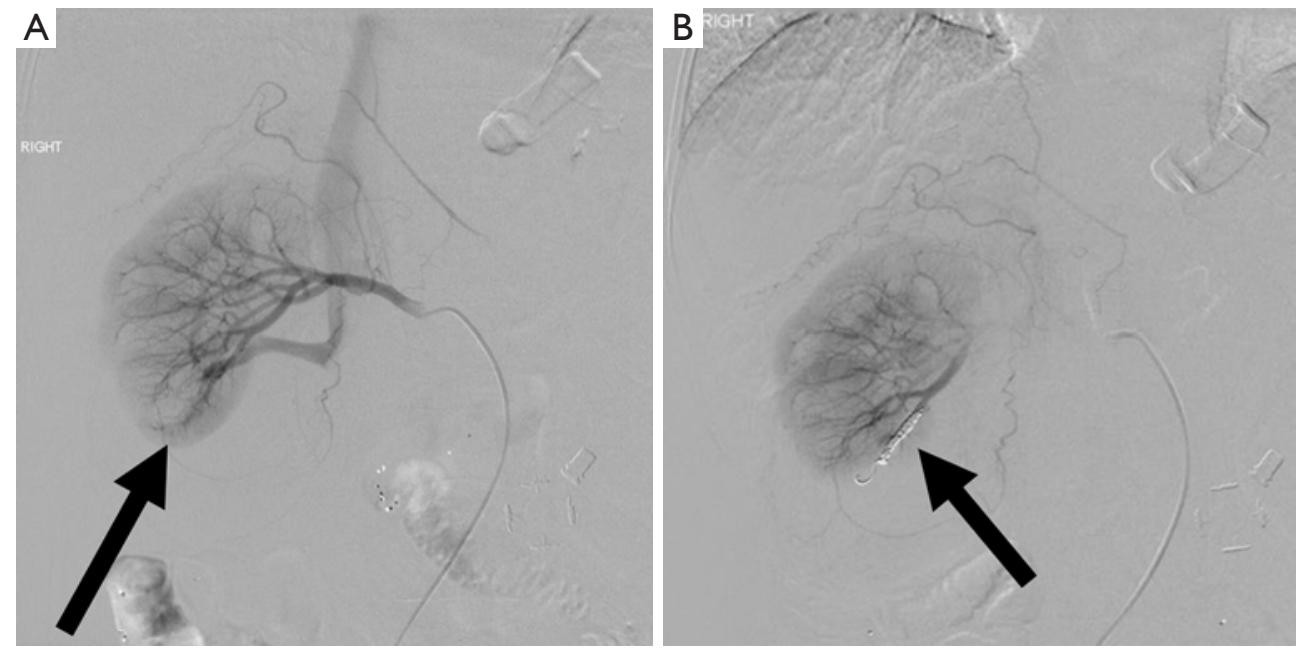

Figure 11 A 46-year-old female with medical renal disease who underwent routine biopsy. Shortly after the biopsy the patient developed gross hematuria. (A) Urgent angiography was performed and demonstrated a pseudoaneurysm arising from a segmental artery in the inferior pole of the right kidney (black arrow). (B) Coil embolization was performed (black arrow) and post embolization angiography demonstrated complete devascularization of the injured artery.

of biopsy, with an odds ratio of 13.6 for patients with a hemoglobin less than 10 (52).

\section{Percutaneous nephrostomy (PCN)}

$\mathrm{PCN}$ is a minimally invasive technique that involves placing a small catheter into the renal collecting system. Four broad indications include relief of obstruction, diagnostic testing such as antegrade pyelography, access for interventions, and urinary diversion (53). The combined major and minor complication rate from $\mathrm{PCN}$ is approximately $10 \%$, with a mortality rate ranging from $0.05-0.3 \%$ (52). One study of 318 PCN cases found a major complication rate of $3.1 \%$, with sepsis being the most commonly reported major complication (2.2\%) (54). Major hemorrhage was encountered in $0.6 \%$ of cases (54) (Figure 12). Death was reported in 2 patients, both due to sepsis (54). Standards of Practice published by the Society of Interventional Radiology summarizes the most commonly encountered major complications from PCN placement, citing septic shock as the most frequent major complication (1-10\%), with rates of septic shock reaching $7-9 \%$ in patient with pyonephrosis (55). Other major complications include hemorrhage requiring transfusion (1-4\%), vascular injury requiring embolization or surgery $(0.1-0.6 \%)$, bowel transgression $(0.2-0.5 \%)$, and pleural injury (0.1-0.6) (55).

\section{Percutaneous cryoablation}

Percutaneous cryoablation is frequently used to treat renal masses, especially in patients who are poor surgical candidates. One multi-institutional review of 271 radiofrequency and cryoablation treating small renal tumors found an overall complication rate of $11 \%(56,57)$. A more recent study of 573 procedures using cryoablation and radiofrequency ablation to treat small renal tumors found an overall complication rate of $11 \%$, with a $6.6 \%$ major complication rate (56). There was no difference in major complication rate between radiofrequency ablation and cryoablation for treating small renal tumors (56). One study looking at only cryoablation found a complication rate of $12.4 \%$ ( $6.5 \%$ major), and a local recurrence rate of $8.3 \%$ (58). The most common complications following renal cryoablation are bleeding and hematuria, with bleeding occurring in $4.8 \%$ of cases (56) (Figure 13). Of the patients that experience bleeding, embolization is indicated in approximately half of cases (56). Increased size and central location of tumors were at greater risk of complication (56). Use of the modified RENAL (mRENAL) score has been shown to be a useful tool in predicting complications and recurrence following renal cryoablation by looking at factors such as lesion size, complexity, and location (exophytic, near collecting system) (58). One study investigating the use of the mRENAL score found that 

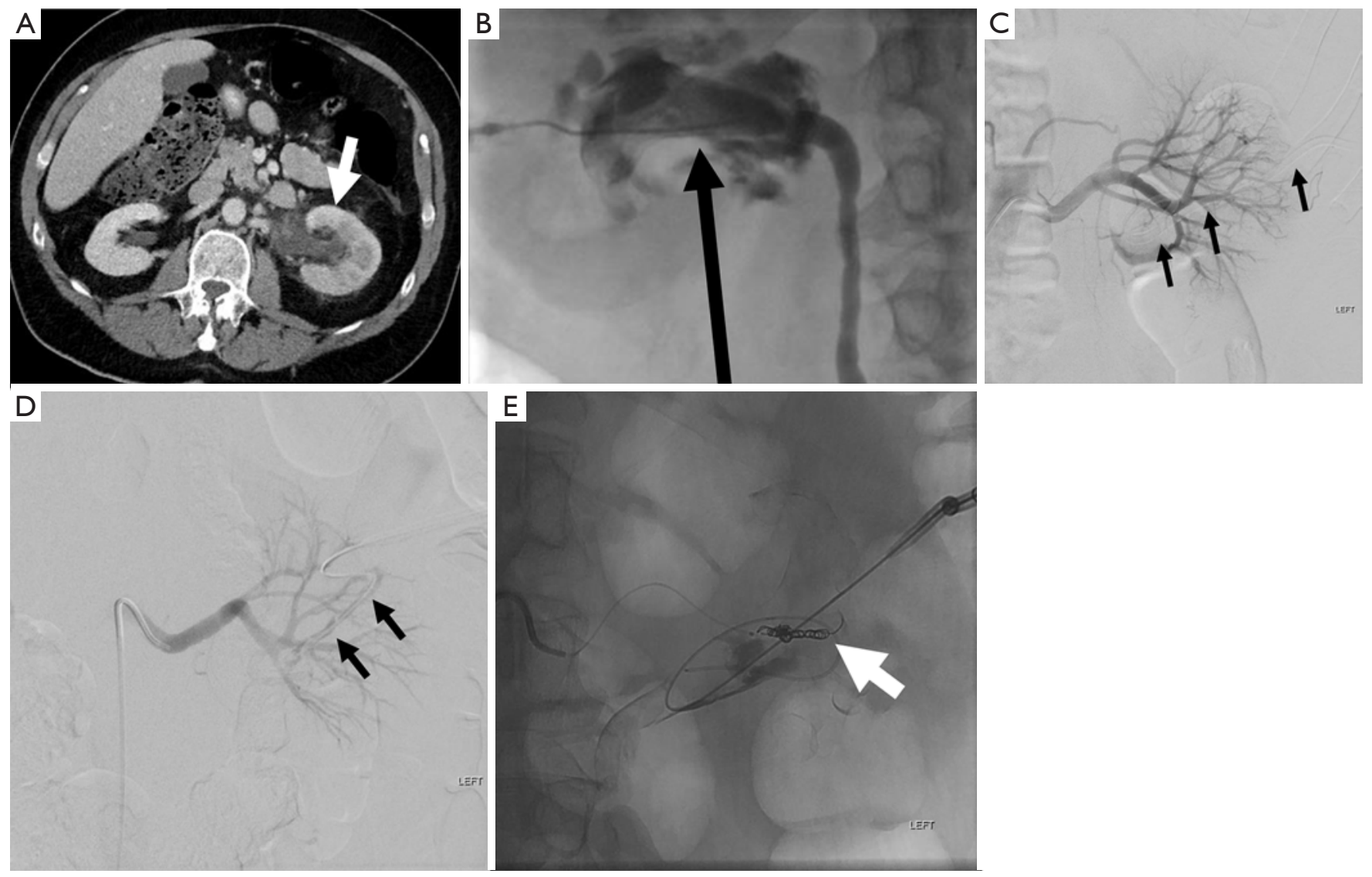

Figure 12 A 71-year-old male with a left ureteral transection during colon resection with need for PCN. (A) CT of the abdomen demonstrated moderate left hydronephrosis (white arrow). (B) A fluoroscopic guided PCN was placed, however the initial puncture was done too centrally (black arrow). Bright red blood was noticed in the PCN bag, and the patient became hypotensive. (C) Urgent angiography was performed; however, no arterial injury was noted while the PCN drain (black arrows) was still in place. (D) The PCN was removed over a wire and repeat digital subtraction angiography was performed, revealing blood along the PCN tract (black arrows). (E) The injured artery was treated with coil embolization (white arrow), leading to resolution of contrast extravasation. PCN, percutaneous nephrostomy.

endophytic location was associated with increased risk of complications, and that only tumor size was associated with increased risk of local recurrence (58).

\section{Percutaneous nephrolithotomy (PCNL)}

PCNL involves percutaneously accessing the renal collecting system for the treatment of renal calculi. Risks and complications of PCNL are similar to PCN, however complication rates tend to be higher than PCN alone (55). Standards of Practice published by the Society of Interventional Radiology reported the most common complication of PCNL was hemorrhage requiring transfusion in $12-14 \%$, followed by pleural complications including pneumothorax, empyema, hemothorax
(8.7-12\%) (55). One recently published systematic review found that the overall complication rate of PCNL was 6.2$15.2 \%$, with ultra-micro equipment being associated with lower overall complications (59). No deaths were reported following PCNL for small to medium sized stones (59).

\section{Endoscopic laser treatments}

Urothelial carcinoma is a malignancy that involves the mucosal surfaces lining of the urinary system (60). The most common site of involvement is the bladder; however, involvement of the ureters and kidneys can be seen in $5-10 \%$ of all urothelial carcinoma (60). The gold standard for treatment of urothelial carcinoma is radical nephroureterectomy with bladder cuff excision (60). More 

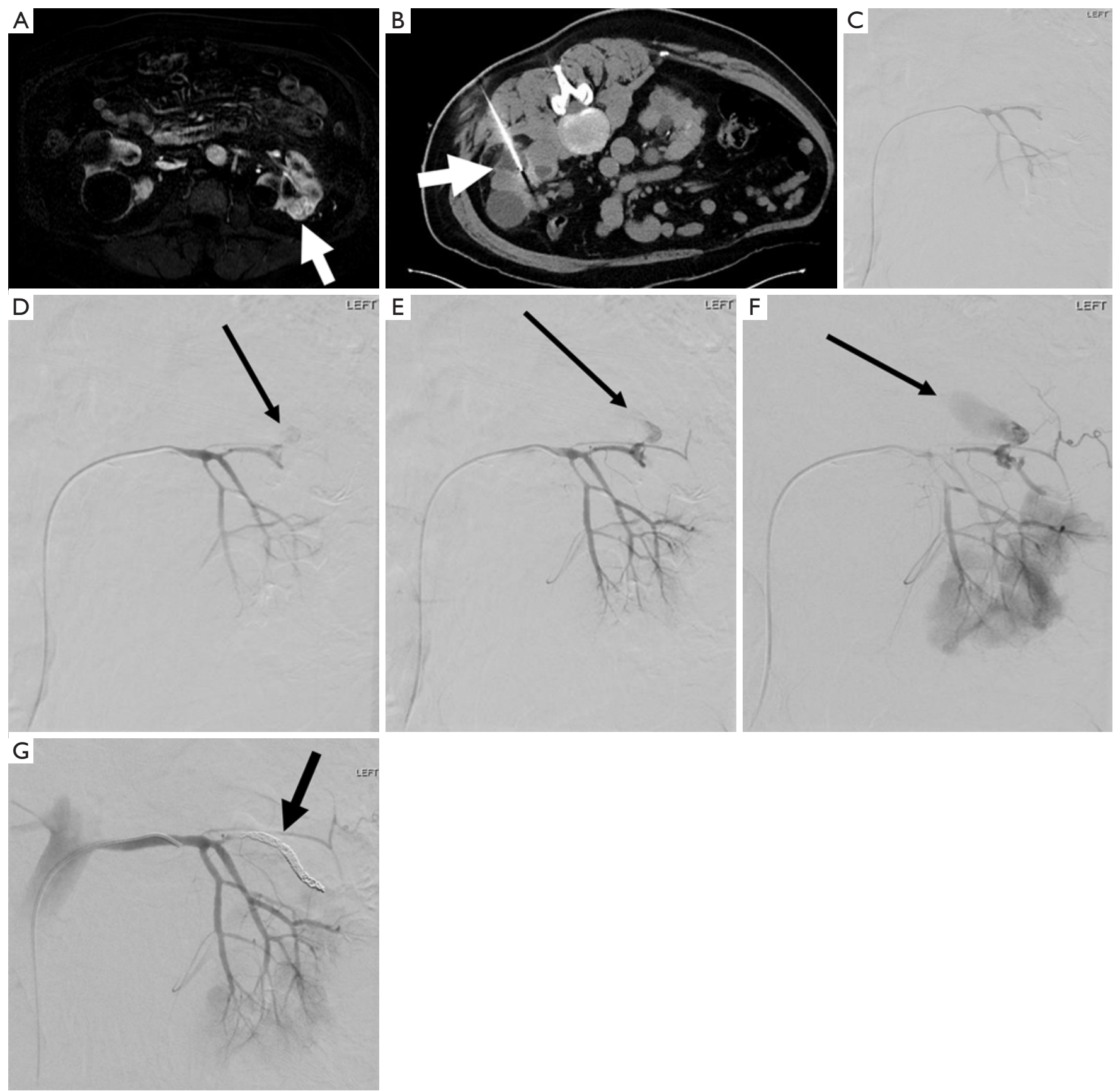

Figure 13 A 66-year-old male with left sided enhancing renal mass, which was biopsy confirmed clear cell renal cell carcinoma (A, white arrow) undergoing a percutaneous cryoablation (B, white arrow). (C,D,E,F) The procedure was complicated by arterial injury, requiring angiography which demonstrated vascular injury and extravasation of contrast (black arrows). (G) Selective coil embolization was performed leading to complete devascularization of the injured artery (black arrow).

recent recommendations published by the European Urology Guidelines recommend endoscopic treatment (including ureteroscopic laser treatment) alone for low grade urothelial malignancies (61). One recently published series of 25 patients treated with ureteroscopic laser ablation of upper pole urothelial carcinoma found that $64 \%$ remained disease free for 3 months, but only one patient remained disease free at 68 months (60). Another series 

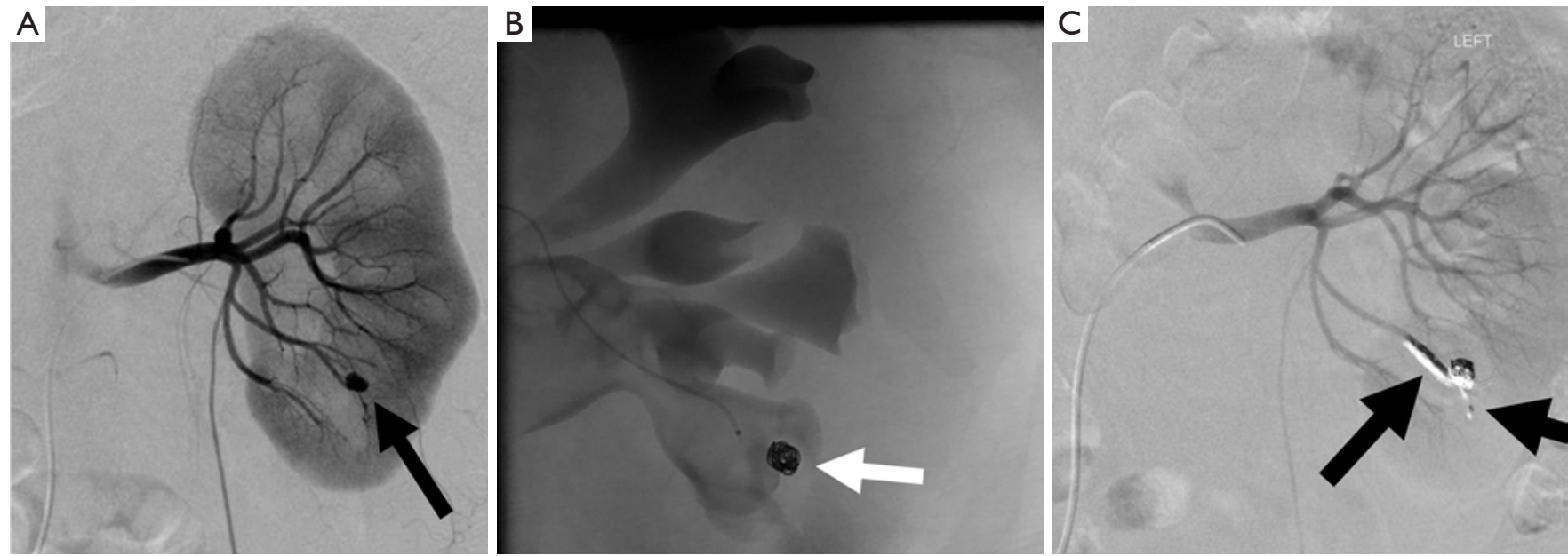

Figure 14 A 66-year-old male with urothelial cancer status post laser ablation with hematuria. (A) Initial angiogram demonstrated a pseudoaneurysm in the inferior pole of the kidney (black arrow). (B) This was treated with coil embolization of the pseudoaneurysm sac (white arrow). Unfortunately, hematuria continued following embolization. (C) Repeat embolization of the feeding vessels was performed (black arrows), which led to a cessation of hematuria.

of 66 patients with low grade upper tract cancer treated with laser ablation reported only $15.2 \%$ progressing to high grade disease (62). Complications included ureteral strictures, bleeding requiring transfusion, sepsis, and severe ureteral injury (60) (Figure 14).

Laser lithotripsy is another technique the urologist can use for renal stone ablation, and has a low overall complication rate, which are mostly attributed to endoscopic access rather than the laser itself (63). The most frequently reported complication from laser lithotripsy is fever, however hematoma and vascular injuries have been reported $(63,64)$.

\section{Partial nephrectomy}

Partial nephrectomy is commonly performed for the treatment of small renal masses. Laparoscopic, robotic assisted, and open techniques are used, with similar oncologic outcomes $(65,66)$. Laparoscopic partial nephrectomies have the advantage of decreased operative time, lower blood loss, and shorter hospital stay, however there are statistically similar complication rates (65). Meta-analysis comparing robotic assisted partial nephrectomy verses open partial nephrectomy found lower blood loss, decreased length of stay, and decreased postoperative complication rates (67-70). Following partial nephrectomy injury to the intrarenal arteries can result in pseudoaneurysm or hematoma, injury to the collecting system, infection, or tumor recurrence (71) (Figure 15). Delayed hemorrhage after partial nephrectomy has been reported in up to $2 \%$ of cases (72). Rates of hemorrhage due to pseudoaneurysm range from $0.4-1.4 \%(73,74)$.

\section{Abdominal}

\section{Paracentesis}

Paracentesis is a commonly performed diagnostic and therapeutic procedure. Bleeding complications are rare, with one observational cohort study with 69,859 paracenteses reporting a bleeding complication rate of $0.8 \%$ (75) (Figure 16). Another study reported the rate of hemorrhage from paracentesis at $0-0.97 \%$, with risk factors for hemorrhage including renal disease, lack of operator experience, and lack of ultrasound guidance (76). Ultrasound guidance has been shown to reduce the risk of bleeding after paracentesis by 3 -fold compared to paracentesis performed without ultrasound (75). One retrospective study including 3,000 paracenteses performed with ultrasound guidance by radiologists found that significant post-paracentesis hemorrhage occurred in only $0.19 \%$ of patients, with only a single case requiring embolization despite the fact that INR was over 2 in $14 \%$ of cases and platelets were under $50 \times 10^{\wedge} 3$ / $\mu \mathrm{L}$ in $12 \%$ of cases (77). Despite the low hemorrhage rate, when blood vessels are injured it is most commonly the inferior epigastric artery or vein, therefore identification of 

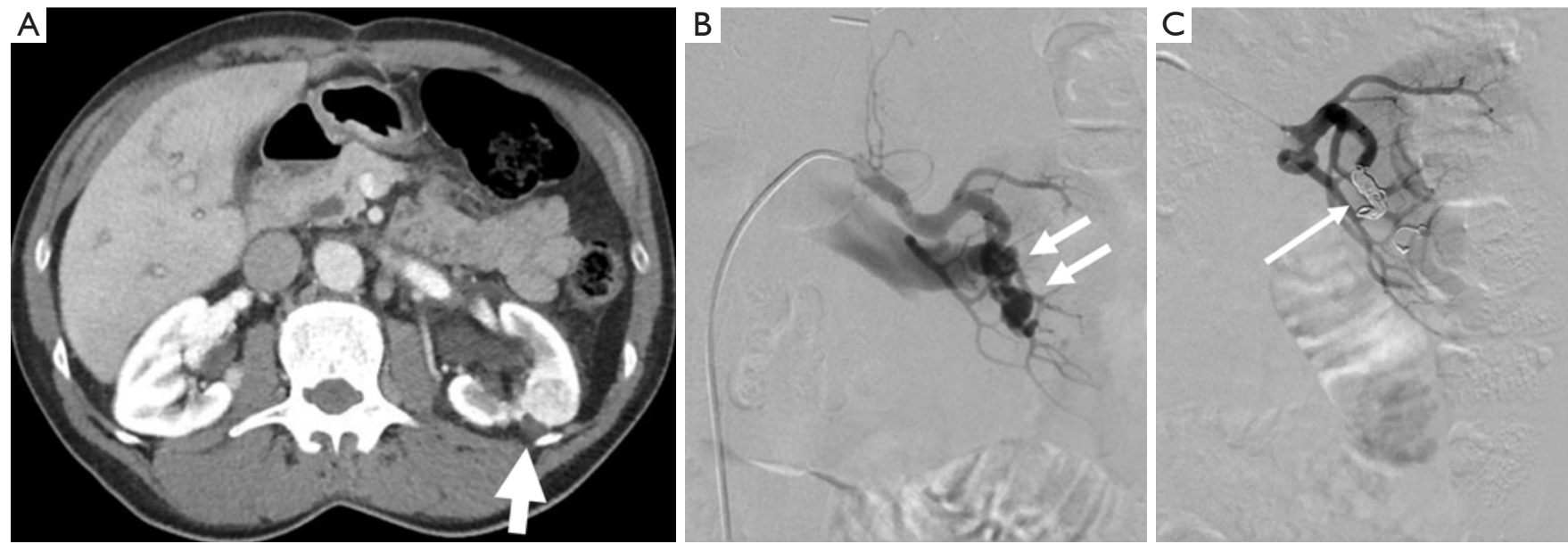

Figure 15 A 67-year-old male with a small papillary renal cell carcinoma, status post partial nephrectomy complicated by gross hematuria. (A) CT of the abdomen demonstrated dense blood adjacent to the nephrectomy defect (white arrow). (B) The patient was taken to angiography, which demonstrated multiple pseudoaneurysms (white arrows). (C) The injured vessels were treated with coil embolization (white arrow).
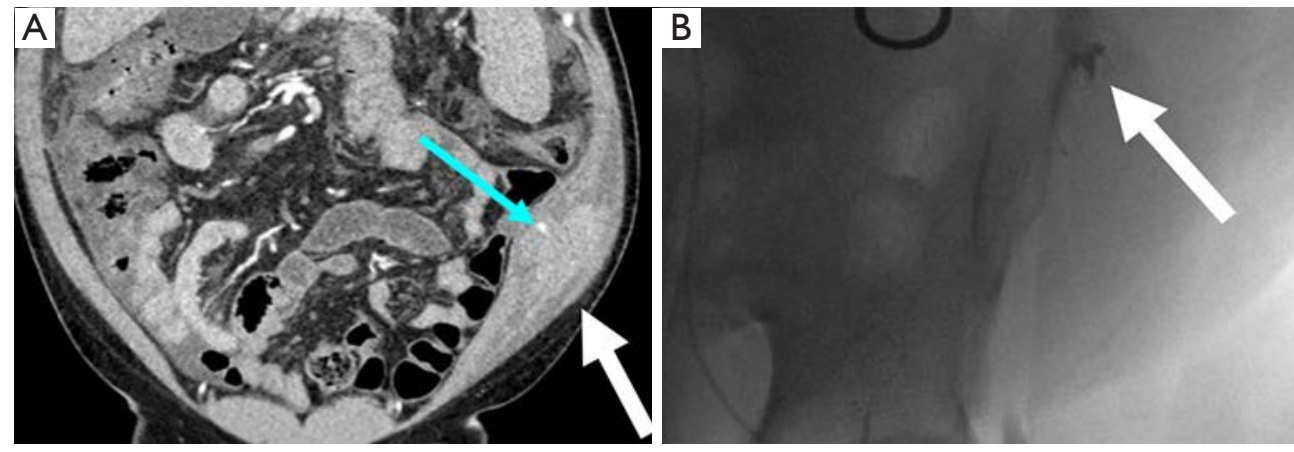

Figure 16 A 52-year-old female with cirrhosis secondary to alcohol use. Following a therapeutic paracentesis without ultrasound for recurrent ascites the patient complained of pain and swelling at the paracentesis site. (A) Coronal CT of the abdomen demonstrated a large rectus sheath hematoma (white arrow), with a focus of active extravasation (blue arrow). (B) Selective angiography with contrast extravasation from the left inferior epigastric artery (white arrow). This was treated with coil embolization (not shown) and the patient's hematoma resolved.

their location by ultrasound prior to paracentesis can further reduce risk of hemorrhage (78).

\section{Drain placement}

Percutaneous drain placement is one of the most commonly performed image guided procedures. Technical success rates are high, often exceeding 90\% (79). Abscess drain is one of the most common indications for percutaneous image guided drain placement, and reduces morbidity and mortality compared to open surgical drainage (80). Overall complication rates from percutaneous abscess drain range from 5-9.8\% (81). Following percutaneous abscess drain placement transient bacteremia is observed in up to $5 \%$ of cases, with septic shock reported in $1-2 \%$ of cases $(79,82)$. Other potential reported complications include hemorrhage requiring transfusion ( $1 \%)$, superinfection of a previously sterile fluid collection (1\%), bowel transgression requiring intervention $(1 \%)$, and pulmonary pleural injury requiring intervention (1\%) (82) (Figure 17). Complication rates are highly dependent on abscess location, patient comorbidities, and provider experience (82). 

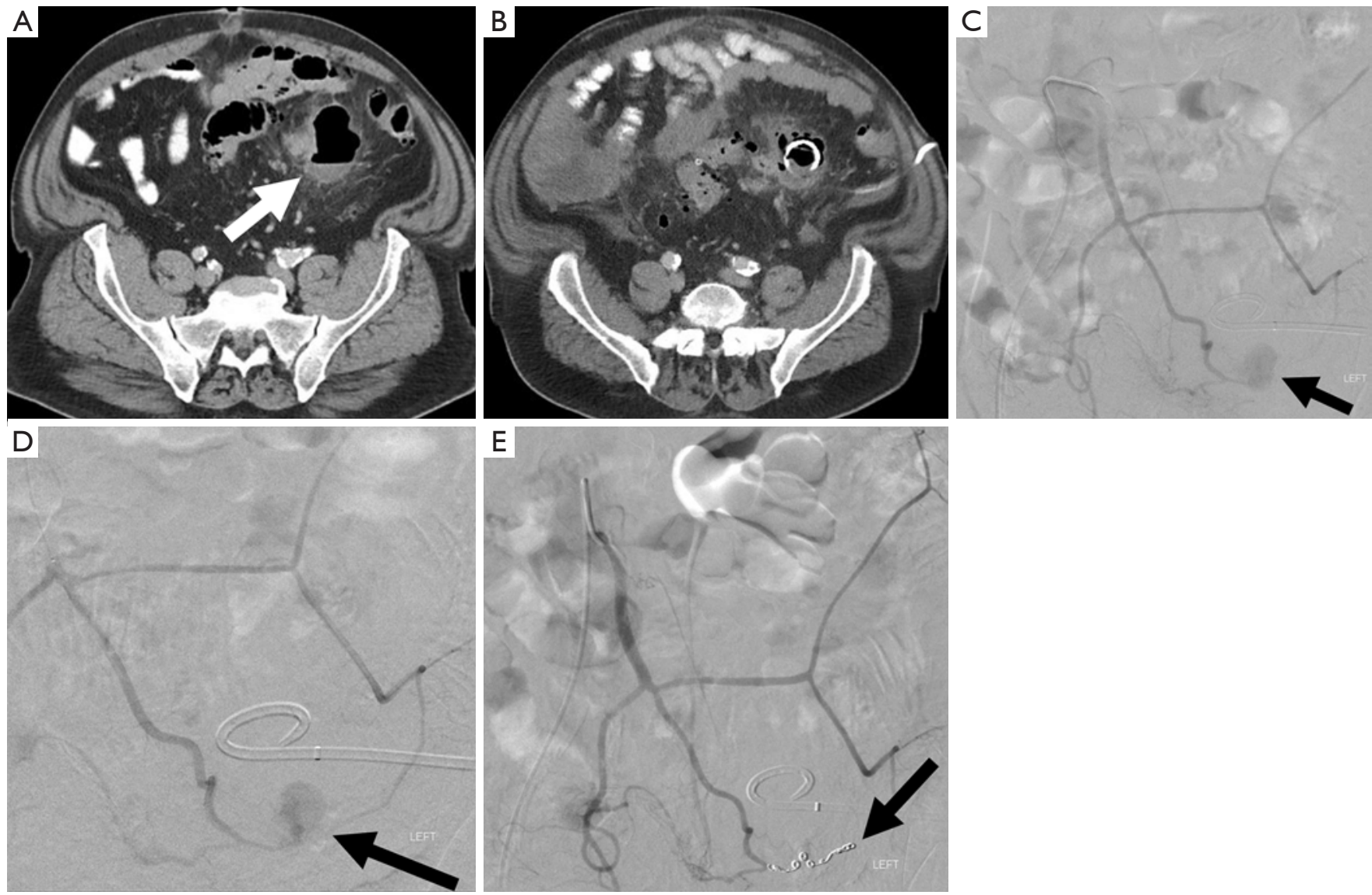

Figure 17 A 66-year-old with diverticular rim enhancing abscess in the left lower quadrant (A, white arrow). (B) A drain was placed into the abscess cavity. After drainage, the patient developed a significant hemoperitoneum (not shown). (C,D) The patient was taken to angiography which demonstrated active extravasation of contrast from an arterial pseudoaneurysm (black arrows). (E) This was treated with coil embolization (black arrow).

\section{Vascular access}

Vascular access allows providers to administer medications, obtain diagnostic labs, and perform diagnostic and therapeutic procedures. Despite advances in techniques, vascular access is not without risk. Arterial catheterization carries a significant bleeding risk of $1.8-2.6 \%$, with risk factors for significant hemorrhage including number of attempts, lack of ultrasound guidance, and a high entry site when accessing the femoral artery (76). Focal arterial injury as a result of catheterization can also occur, resulting in pseudoaneurysm. The most commonly accessed artery is the common femoral artery (CFA), and risk factors for pseudoaneurysm development at the CFA include advanced age, female gender, obesity, hypertension, sheaths greater than $6 \mathrm{~F}$ in size, post procedure anticoagulation use, and periprocedural $\mathrm{P} 2 \mathrm{Y} 12$ inhibitor use (83) (Figure 18). Treatment depends on the characteristics and size of the pseudoaneurysm and can include compression, injection of thrombin into the pseudoaneurysm, or surgical repair (84).

When venous access is attempted, there is a risk of inadvertent arterial access or arterial injury. Without ultrasound guidance the risk of accidental arterial access is $15 \%$, but with ultrasound guidance the risk drops to $1 \%(85,86)$. When accidental arterial access occurs, management usually involves endovascular or open surgical removal and vessel repair $(85,86)$ (Figure 19). Other factors that contribute to arterial injury include previous radiotherapy, obesity, lack of operator experience, previous surgery at site of vascular access, and multiple venous access attempts $(85,86)$. In addition to inadvertent arterial access other potential complications include hematoma, 

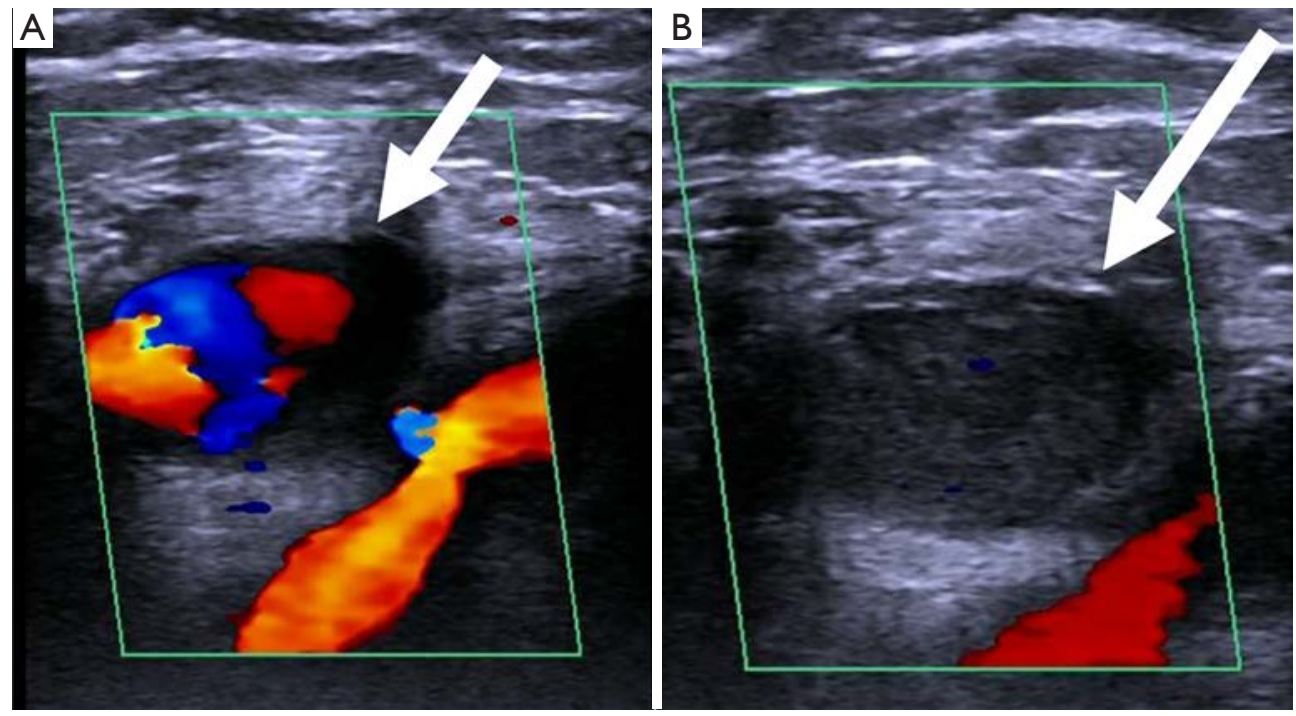

Figure 18 A 59-year-old female status post right common femoral artery arterial access who presented with increasing right groin pain and swelling. (A) Ultrasound demonstrated a narrow necked pseudoaneurysm with the classic "yin-yang" appearance on doppler ultrasound (white arrow). (B) This was treated with thrombin injection, which led to complete thrombosis of the pseudoaneurysm (white arrow).
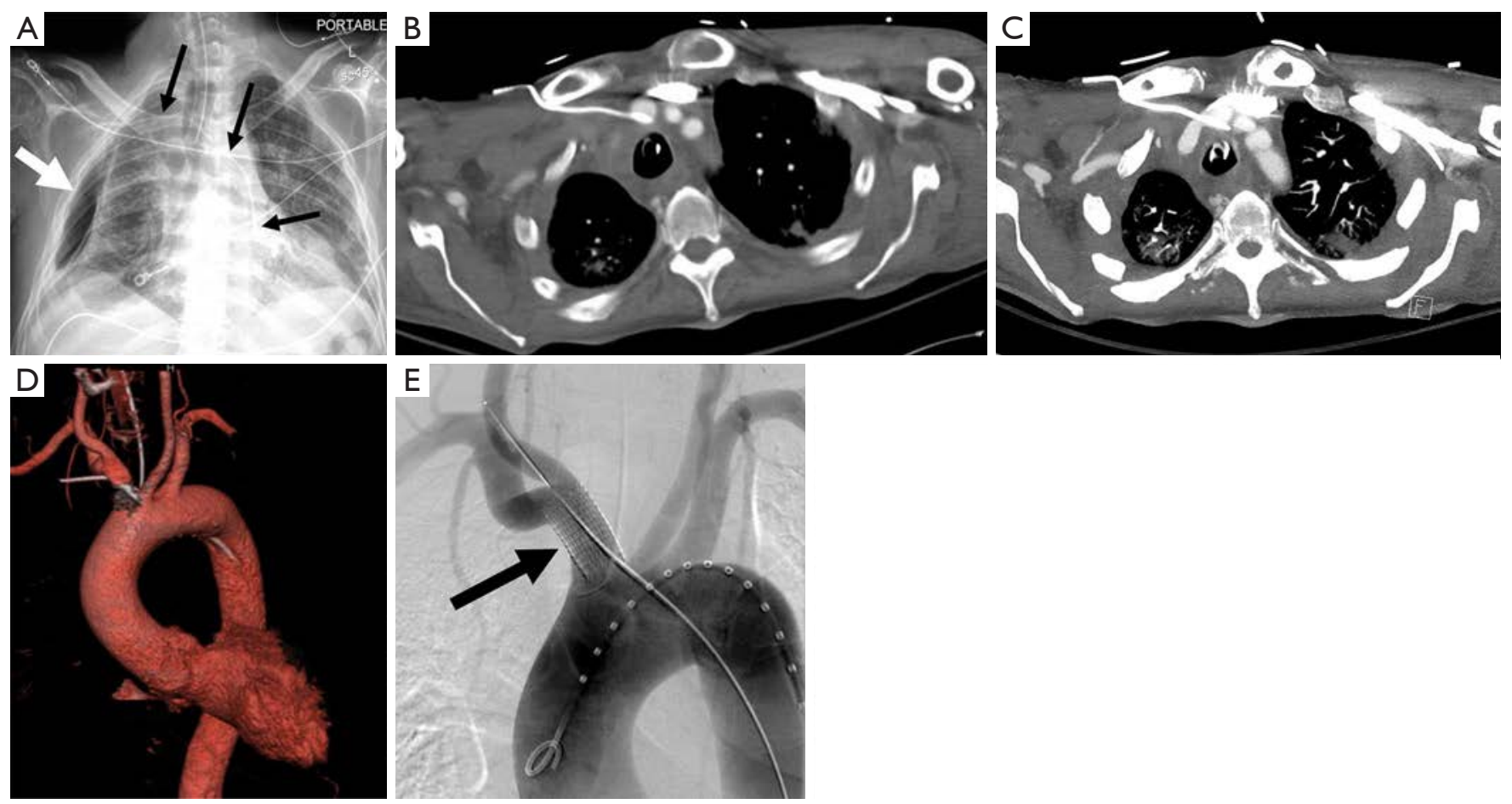

Figure 19 A 59-year-old male status post bedside central line placement. The procedure was complicated by pneumothorax and inadvertent arterial placement. (A) Chest radiograph demonstrating a right sided pneumothorax (white arrow), and a central line which crosses midline and terminates near the level of the left main bronchus, consistent with inadvertent arterial access (black arrows). (B-D) Axial contrast enhanced CT, maximum intensity projection images, and 3D reconstruction of the aorta and great vessels all demonstrating the catheter entering the right brachiocephalic artery and coursing into the descending aorta. (E) This required treatment with endovascular stent graft placement over the arterial puncture site in the right brachiocephalic artery (black arrow). 


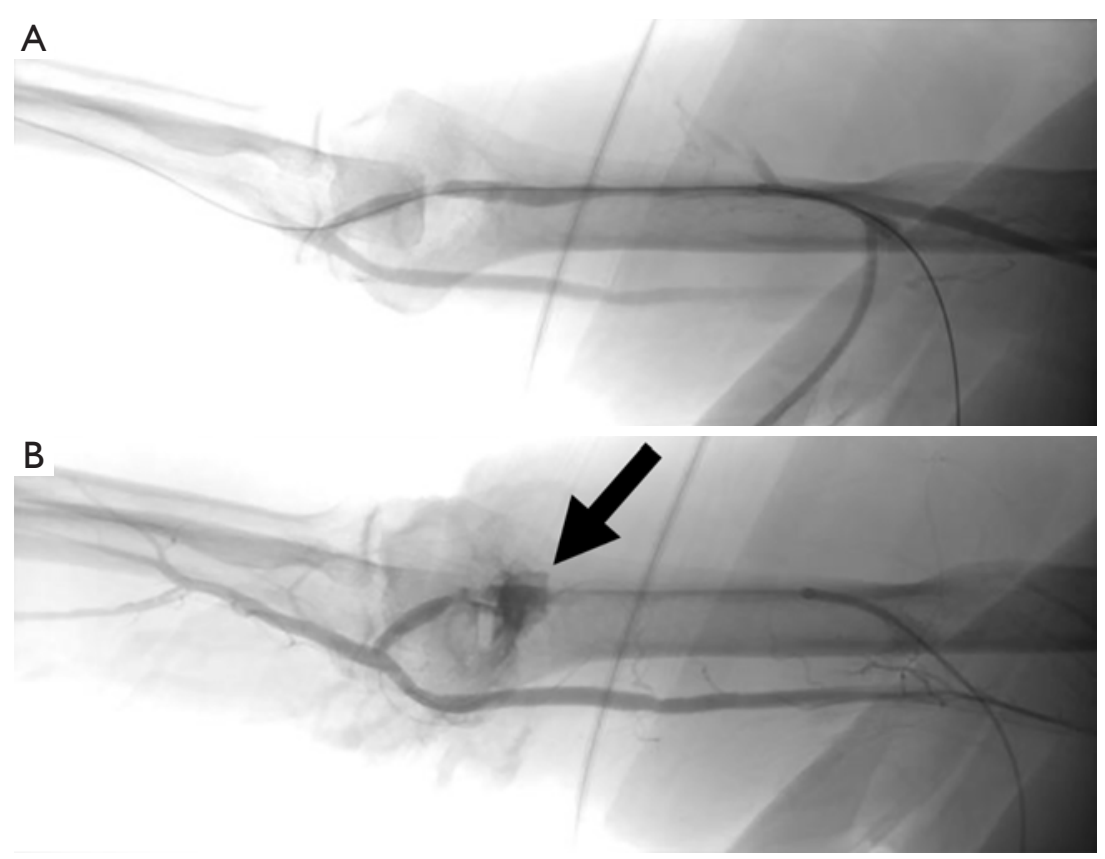

Figure 20 A 47-year-old female with end stage renal disease and an arteriovenous fistula with slow flow. (A) Angiographic images of the arteriovenous fistula demonstrating stenosis, which was treated with balloon angioplasty. (B) Angioplasty caused a vascular rupture (black arrow) which was treated with prolonged balloon inflation.

hemothorax, pseudoaneurysms, dissection, AV fistula, limb ischemia, stroke, or death $(85,86)$.

\section{Dialysis interventions}

The number of patients treated with dialysis has been steadily increasing every year, and adequate vascular access is needed for long term dialysis (87). Arteriovenous fistulas and arteriovenous grafts are two commonly used methods for dialysis access, however these are prone to stenosis (87). Percutaneous interventions can be used to maintain patency and increase the life of the fistula or graft (87). Angioplasty is commonly used to treat graft and fistula stenosis over $50 \%(87,88)$. Multiple studies have reported 50\% success using angioplasty for maintenance of graft and fistula patency at 6-month and 1-year (89-91). The most common complication of angioplasty is vessel rupture, which can often be treated with temporary balloon tamponade or stent placement (92) (Figure 20). Cutting balloons and inappropriate balloon selection has been shown to increase the risk of rupture without increase in patency rates $(93,94)$.

\section{Musculoskeletal}

\section{Bone marrow biopsy}

Iatrogenic injury during bone marrow biopsy is rare, but has been reported in the literature (95). Reported cases of arterial injury include circumflex iliac artery, iliolumbar artery, superior gluteal artery, median sacral artery, and anterior hypogastric artery (86,96-101). Although complication is rare, the most commonly reported complications include infection, hemorrhage, nerve injury, fracture, or needle tract seeding (95) (Figure 21).

\section{Discussion and summary}

Iatrogenic injury is an unfortunate risk of medical intervention. Adequate training, experience, and image guidance (such as real time ultrasound) can lower procedure complication rates; however, complications are not completely avoidable. Prompt recognition of iatrogenic injury and appropriate triage for further treatment can improve patient outcomes. Minimally invasive endovascular 

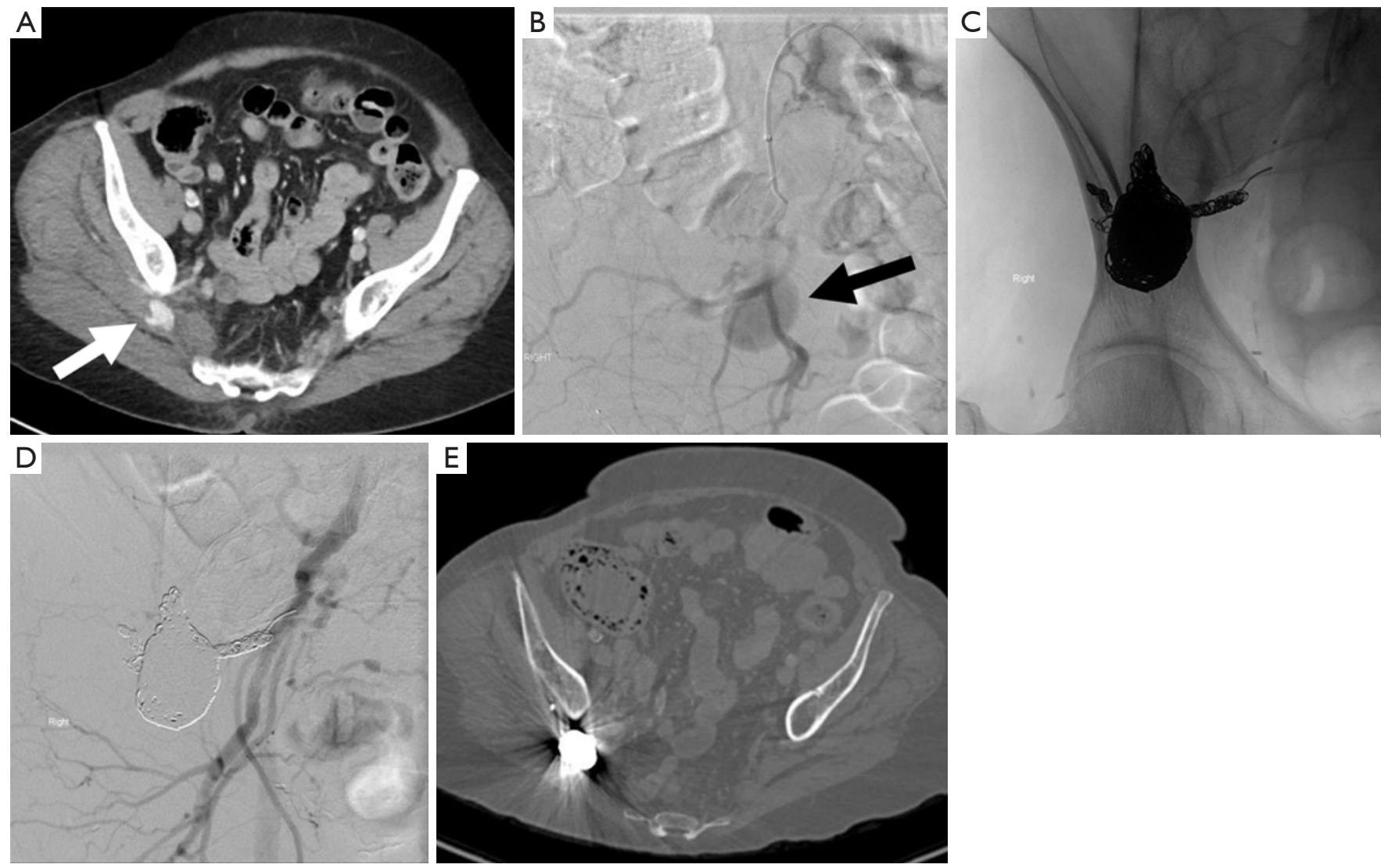

Figure 21 A 71-year-old female status post bone marrow biopsy with back and hip pain. (A) Contrast enhanced CT of the abdomen and pelvis demonstrating a large pseudoaneurysm (white arrow) in the expected location of the superficial circumflex iliac artery. (B) Angiographic images of the internal iliac artery demonstrating a large pseudoaneurysm (black arrow) arising from the right superficial circumflex iliac artery. (C,D,E) This was treated with coil embolization.

treatment is a potential option for patients with iatrogenic vascular injury in certain cases. Given the nature of iatrogenic injury, much of the reviewed research was either retrospective or case reports, and thus limited by their design. Further research is needed to help identify risk factors that would place a patient at greater risk of harm than benefit from an intervention. Further research is also needed to better define outcomes for patients with iatrogenic vascular injury treated with minimally invasive endovascular techniques verses conservative management or surgical intervention.

\section{Acknowledgments}

Finding: None.

\section{Footnote}

Provenance and Peer Review: This article was commissioned by the Guest Editor (Keith Bertram Quencer) for the series "Endovascular interventions in trauma" published in Annals of Translational Medicine. The article was sent for external peer review organized by the Guest Editor and the editorial office.

Reporting Checklist: The authors have completed the Narrative Review reporting checklist. Available at http:// dx.doi.org/10.21037/atm-20-4332

Conflicts of Interest: All authors have completed the ICMJE uniform disclosure form (available at http://dx.doi. 


\section{Page 18 of 21}

org/10.21037/atm-20-4332). The series "Endovascular interventions in trauma" was commissioned by the editorial office without any funding or sponsorship. KBQ served as the unpaid Guest Editor of the series and serves as an unpaid editorial board member of Annals of Translational Medicine from Aug 2019 to Jul 2021. The authors have no other conflicts of interest to declare.

Ethical Statement: The authors are accountable for all aspects of the work in ensuring that questions related to the accuracy or integrity of any part of the work are appropriately investigated and resolved.

Open Access Statement: This is an Open Access article distributed in accordance with the Creative Commons Attribution-NonCommercial-NoDerivs 4.0 International License (CC BY-NC-ND 4.0), which permits the noncommercial replication and distribution of the article with the strict proviso that no changes or edits are made and the original work is properly cited (including links to both the formal publication through the relevant DOI and the license). See: https://creativecommons.org/licenses/by-nc-nd/4.0/.

\section{References}

1. The World Health Organization. Cancer [Internet]. 2018 [updated 2018 Sept 12; cited 2020 Aug 5]. Available online: https://www.who.int/news-room/fact-sheets/detail/cancer

2. Heerink WJ, de Bock GH, de Jonge GJ, et al. Complication rates of CT-guided transthoracic lung biopsy: meta-analysis. Eur Radiol 2017;27:138-48.

3. Marchak K, Hong MJ, Schramm KM. Systemic Air Embolism following CT-Guided Percutaneous Core Needle Biopsy of the Lung: Case Report and Review of the Literature. Semin Intervent Radiol 2019;36:068-71.

4. Elshafee AS, Karch A, Ringe KI, et al. Complications of CT-guided lung biopsy with a non-coaxial semi-automated 18 gauge biopsy system: Frequency, severity and risk factors. Cronin P, editor. PLoS One 2019;14:e0213990.

5. Tai R, Dunne RM, Trotman-Dickenson B, et al. Frequency and Severity of Pulmonary Hemorrhage in Patients Undergoing Percutaneous CT-guided Transthoracic Lung Biopsy: Single-Institution Experience of 1175 Cases. Radiology 2016;279:287-96.

6. Bou Zein Eddine S, Boyle KA, Dodgion CM, et al. Observing pneumothoraces. J Trauma Acute Care Surg 2019;86:557-64.

7. American Society of Anesthesiologists Task Force on

\section{Smith et al. Endovascular management of iatrogenic trauma}

Pulmonary Artery Catheterization. Practice Guidelines for Pulmonary Artery Catheterization. Anesthesiology 2003;99:988-1014.

8. Abreu AR, Campos MA, Krieger BP. Pulmonary Artery Rupture Induced by a Pulmonary Artery Catheter: A Case Report and Review of the Literature. J Intensive Care Med 2004;19:291-6.

9. Evans DC, Doraiswamy VA, Prosciak MP, et al. Complications Associated with Pulmonary Artery Catheters: A Comprehensive Clinical Review. Scand J Surg 2009;98:199-208.

10. Ahsan K, Hamid M, Fatimi S, et al. Right ventricular perforation: a rare complication of pulmonary artery catheterization. J Coll Physicians Surg Pak 2014;24 Suppl 3:S166-8.

11. Ray CE, Kaufman JA, Geller SC, et al. Embolization of Pulmonary Catheter-Induced Pulmonary Artery Pseudoaneurysms. Chest 1996;110:1370-3.

12. Hernandez MC, El Khatib M, Prokop L, et al. Complications in tube thoracostomy. J Trauma Acute Care Surg 2018;85:410-6.

13. Hernandez MC, Zeb MH, Heller SF, et al. Tube Thoracostomy Complications Increase Cost. World J Surg 2017;41:1482-7.

14. Davidson JC, Rahim S, Hanks SE, et al. Society of Interventional Radiology Consensus Guidelines for the Periprocedural Management of Thrombotic and Bleeding Risk in Patients Undergoing Percutaneous ImageGuided Interventions-Part I: Review of Anticoagulation Agents and Clinical Considerations. J Vasc Interv Radiol 2019;30:1155-67.

15. Cantey EP, Walter JM, Corbridge T, et al. Complications of thoracentesis. Curr Opin Pulm Med 2016;22:378-85.

16. Ault MJ, Rosen BT, Scher J, et al. Thoracentesis outcomes: a 12-year experience. Thorax 2015;70:127-32.

17. Schildhouse R, Lai A, Barsuk JH, et al. Safe and Effective Bedside Thoracentesis: A Review of the Evidence for Practicing Clinicians. J Hosp Med 2017;12:266-76.

18. Salamonsen M, Dobeli K, McGrath D, et al. Physicianperformed ultrasound can accurately screen for a vulnerable intercostal artery prior to chest drainage procedures. Respirology 2013;18:942-7.

19. Patel PA, Ernst FR, Gunnarsson CL. Ultrasonography guidance reduces complications and costs associated with thoracentesis procedures. J Clin Ultrasound 2012;40:135-41.

20. Gupta P, Maralakunte M, Rathee S, et al. Percutaneous transhepatic biliary drainage in patients at higher risk for 
adverse events: experience from a tertiary care referral center. Abdom Radiol (NY) 2020;45:2547-53.

21. Quencer KB, Tadros A, Marashi K, et al. Bleeding after Percutaneous Transhepatic Biliary Drainage: Incidence, Causes and Treatments. J Clin Med 2018;7:94.

22. Duan F, Cui L, Bai Y, et al. Comparison of efficacy and complications of endoscopic and percutaneous biliary drainage in malignant obstructive jaundice: a systematic review and meta-analysis. Cancer Imaging 2017;17:27.

23. Giurazza F, Corvino F, Contegiacomo A, et al. Safety and effectiveness of ultrasound-guided percutaneous transhepatic biliary drainage: a multicenter experience. J Ultrasound 2019;22:437-45.

24. Berger D, Desai V, Janardhan S. Con: Liver Biopsy Remains the Gold Standard to Evaluate Fibrosis in Patients With Nonalcoholic Fatty Liver Disease. Clin Liver Dis (Hoboken) 2019;13:114-6.

25. Li XH, Liang Q, Chen TW, et al. Diagnostic value of imaging examinations in patients with primary hepatocellular carcinoma. World J Clin Cases 2018;6:242-8.

26. Midia M, Devang O, Shuster A, et al. Predictors of bleeding complications following percutaneous imageguided liver biopsy: a scoping review. Diagn Interv Radiol 2019;25:71-80.

27. Seeff LB, Everson GT, Morgan TR, et al. Complication Rate of Percutaneous Liver Biopsies Among Persons With Advanced Chronic Liver Disease in the HALT-C Trial. Clin Gastroenterol Hepatol 2010;8:877-83.

28. Thampanitchawong P, Piratvisuth T. Liver biopsy: complications and risk factors. World J Gastroenterol 1999;5:301-4.

29. Suhocki PV, Lungren M, Kapoor B, et al. Transjugular Intrahepatic Portosystemic Shunt Complications: Prevention and Management. Semin Intervent Radiol 2015;32:123-32.

30. Gaba RC, Khiatani VL, Knuttinen MG, et al. Comprehensive Review of TIPS Technical Complications and How to Avoid Them. AJR Am J Roentgenol 2011;196:675-85.

31. Petit P, Lazar I, Chagnaud C, et al. Iatrogenic dissection of the portal vein during TIPS procedure. Eur Radiol 2000;10:930-4.

32. Fidelman N, Kwan SW, LaBerge JM, et al. The Transjugular Intrahepatic Portosystemic Shunt: An Update. AJR Am J Roentgenol 2012;199:746-55.

33. Liu K. Delayed liver laceration following transjugular intrahepatic portosystemic shunt for portal hypertension. World J Gastroenterol 2012;18:7405.
34. Clark TW. Complications of Hepatic Chemoembolization. Semin Intervent Radiol 2006;23:119-25.

35. Yoon DY, Park JH, Chung JW, et al. Iatrogenic dissection of the celiac artery and its branches during transcatheter arterial embolization for hepatocellular carcinoma: Outcome in 40 patients. Cardiovasc Intervent Radiol 1995;18:16-9.

36. Reed RA, Teitelbaum GP, Daniels JR, et al. Prevalence of Infection Following Hepatic Chemoembolization with Cross-linked Collagen with Administration of Prophylactic Antibiotics. J Vasc Interv Radiol 1994;5:367-71.

37. Olson MC, Atwell TD, Harmsen WS, et al. Safety and Accuracy of Percutaneous Image-Guided Core Biopsy of the Spleen. AJR Am J Roentgenol 2016;206:655-9.

38. Lindgren PG, Hagberg H, Eriksson B, et al. Excision biopsy of the spleen by ultrasonic guidance. Br J Radiol 1985;58:853-7.

39. Keogan MT, Freed KS, Paulson EK, et al. Imagingguided percutaneous biopsy of focal splenic lesions: update on safety and effectiveness. AJR Am J Roentgenol 1999;172:933-7.

40. McInnes MDF, Kielar AZ, Macdonald DB. Percutaneous Image-guided Biopsy of the Spleen: Systematic Review and Meta-Analysis of the Complication Rate and Diagnostic Accuracy. Radiology 2011;260:699-708.

41. Tam A, Krishnamurthy S, Pillsbury EP, et al. Percutaneous Image-guided Splenic Biopsy in the Oncology Patient: An Audit of 156 Consecutive Cases. J Vasc Interv Radiol 2008;19:80-7.

42. Gómez-Rubio M, López-Cano A, Rendón P, et al. Safety and diagnostic accuracy of percutaneous ultrasoundguided biopsy of the spleen: A multicenter study. J Clin Ultrasound 2009;37:445-50.

43. Siniluoto T, Päivänsalo M, Tikkakoski T, et al. UltrasoundGuided Aspiration Cytology of the Spleen. Acta Radiol 1992;33:137-9.

44. Patel N, Dawe G, Tung K. Ultrasound-guided percutaneous splenic biopsy using an $18-\mathrm{G}$ core biopsy needle: our experience with 52 cases. Br J Radiol 2015;88:20150400.

45. Talwar A, Gabr A, Riaz A, et al. Adverse Events Related to Partial Splenic Embolization for the Treatment of Hypersplenism: A Systematic Review. J Vasc Interv Radiol 2020;31:1118-31.e6.

46. Gu JJ, He XH, Li WT, et al. Safety and efficacy of splenic artery coil embolization for hypersplenism in liver cirrhosis. Acta Radiol 2012;53:862-7.

47. Petit P, Bret PM, Atri M, et al. Splenic vein thrombosis 
after splenectomy: frequency and role of imaging.

Radiology 1994;190:65-8.

48. Bundy JJ, Hage AN, Srinivasa RN, et al. Intra-arterial ampicillin and gentamicin and the incidence of splenic abscesses following splenic artery embolization: A 20-year case control study. Clin Imaging 2019;54:6-11.

49. Ekeh AP, Khalaf S, Ilyas S, et al. Complications arising from splenic artery embolization: a review of an 11-year experience. Am J Surg 2013;205:250-4.

50. Lee WS, Choi ST, Kim KK. Splenic Abscess: A Single Institution Study and Review of the Literature. Yonsei Med J 2011;52:288.

51. Liu YH, Liu CP, Lee CM. Splenic abscesses at a tertiary medical center in northern Taiwan. J Microbiol Immunol Infect 2014;47:104-8.

52. Palsson R, Short SAP, Kibbelaar ZA, et al. Bleeding Complications After Percutaneous Native Kidney Biopsy: Results From the Boston Kidney Biopsy Cohort. Kidney Int Rep 2020;5:511-8.

53. Feldmann Y, Böer K, Wolf G, et al. Complications and monitoring of percutaneous renal biopsy - a retrospective study. Clin Nephrol 2018;89:260-8.

54. Lewis S, Patel U. Major complications after percutaneous nephrostomy-lessons from a department audit. Clin Radiol 2004;59:171-9.

55. Pabon-Ramos WM, Dariushnia SR, Walker TG, et al. Quality Improvement Guidelines for Percutaneous Nephrostomy. J Vasc Interv Radiol 2016;27:410-4.

56. Atwell TD, Carter RE, Schmit GD, et al. Complications following 573 Percutaneous Renal Radiofrequency and Cryoablation Procedures. J Vasc Interv Radiol 2012;23:48-54.

57. Johnson DB, Solomon SB, Su LM, et al. Defining the complications of cryoablation and radio frequency ablation of small renal tumors: a multi-institutional review. J Urol 2004;172:874-7.

58. Mouli SK, McDevitt JL, Su YK, et al. Analysis of the RENAL and mRENAL Scores and the Relative Importance of Their Components in the Prediction of Complications and Local Progression after Percutaneous Renal Cryoablation. J Vasc Interv Radiol 2017;28:860-7.

59. Jones P, Elmussareh M, Aboumarzouk OM, et al. Role of Minimally Invasive (Micro and Ultra-mini) PCNL for Adult Urinary Stone Disease in the Modern Era: Evidence from a Systematic Review. Curr Urol Rep 2018;19:27.

60. Kalaitzis C, Zisimopoulos A, Giannakopoulos S, et al. Ureteroscopic Laser Treatment of Upper Urinary Tract Urothelial Cell Carcinomas: Can a Tumour Free Status Be
Achieved? Adv Urol 2013;2013:429585.

61. Rouprêt M, Zigeuner R, Palou J, et al. European Guidelines for the Diagnosis and Management of Upper Urinary Tract Urothelial Cell Carcinomas: 2011 Update. Eur Urol 2011;59:584-94.

62. Grasso M, Fishman AI, Cohen J, et al. Ureteroscopic and extirpative treatment of upper urinary tract urothelial carcinoma: a 15-year comprehensive review of 160 consecutive patients. BJU Int 2012;110:1618-26.

63. Kronenberg P, Somani B. Advances in Lasers for the Treatment of Stones-a Systematic Review. Curr Urol Rep 2018;19:45.

64. Zhang $\mathrm{P}, \mathrm{Hu}$ WL. Sudden onset of a huge subcapsular renal hematoma following minimally invasive ureteroscopic holmium laser lithotripsy: A case report. Exp Ther Med 2015;10:335-7.

65. Reifsnyder JE, Ramasamy R, Ng CK, et al. Laparoscopic and Open Partial Nephrectomy: Complication Comparison Using the Clavien System. JSLS 2012;16:38-44.

66. Gul ZG, Tam A, Badani KK. Robotic partial nephrectomy: The current status. Indian J Urol 2020;36:16-20.

67. Cacciamani GE, Medina LG, Gill T, et al. Impact of Surgical Factors on Robotic Partial Nephrectomy Outcomes: Comprehensive Systematic Review and MetaAnalysis. J Urol 2018;200:258-74.

68. Wu Z, Li M, Liu B, et al. Robotic versus Open Partial Nephrectomy: A Systematic Review and Meta-Analysis. Coppola D, editor. PLoS One 2014;9:e94878.

69. Shen Z, Xie L, Xie W, et al. The comparison of perioperative outcomes of robot-assisted and open partial nephrectomy: a systematic review and meta-analysis. World J Surg Oncol 2016;14:220.

70. Xia L, Wang X, Xu T, et al. Systematic Review and MetaAnalysis of Comparative Studies Reporting Perioperative Outcomes of Robot-Assisted Partial Nephrectomy Versus Open Partial Nephrectomy. J Endourol 2017;31:893-909.

71. Israel GM, Hecht E, Bosniak MA. CT and MR Imaging of Complications of Partial Nephrectomy. RadioGraphics 2006;26:1419-29.

72. Ramani AP, Desai MM, Steinberg AP, et al. Complications of laparoscopic partial nephrectomy in 200 cases. J Urol 2005;173:42-7.

73. Singh D, Gill IS. Renal artery pseudoaneurysm following laparoscopic partial nephrectomy. J Urol 2005;174:2256-9.

74. Albani JM, Novick AC. Renal artery pseudoaneurysm after partial nephrectomy: three case reports and a literature review. Urology 2003;62:227-31. 
75. Mercaldi CJ, Lanes SF. Ultrasound Guidance Decreases Complications and Improves the Cost of Care Among Patients Undergoing Thoracentesis and Paracentesis. Chest 2013;143:532-8.

76. Wolfe KS, Kress JP. Risk of Procedural Hemorrhage. Chest 2016;150:237-46.

77. Rowley MW, Agarwal S, Seetharam AB, et al. RealTime Ultrasound-Guided Paracentesis by Radiologists: Near Zero Risk of Hemorrhage without Correction of Coagulopathy. J Vasc Interv Radiol 2019;30:259-64.

78. Sobkin PR, Bloom AI, Wilson MW, et al. Massive Abdominal Wall Hemorrhage from Injury to the Inferior Epigastric Artery: A Retrospective Review. J Vasc Interv Radiol 2008;19:327-32.

79. Lorenz J, Thomas JL. Complications of percutaneous fluid drainage. Semin Intervent Radiol 2006;23:194-204.

80. Brolin RE, Nosher JL, Leiman S, et al. Percutaneous catheter versus open surgical drainage in the treatment of abdominal abscesses. Am Surg 1984;50:102-8.

81. Roberts BW. CT-guided Intra-abdominal Abscess Drainage. Radiol Technol 2015;87:187CT-203CT.

82. Wallace MJ, Chin KW, Fletcher TB, et al. Quality Improvement Guidelines for Percutaneous Drainage/ Aspiration of Abscess and Fluid Collections. J Vasc Interv Radiol 2010;21:431-5.

83. Naddaf A, Williams S, Hasanadka R, et al. Predictors of Groin Access Pseudoaneurysm Complication: A 10Year Institutional Experience. Vasc Endovascular Surg 2020;54:42-6.

84. Morgan R, Belli AM. Current Treatment Methods for Postcatheterization Pseudoaneurysms. J Vasc Interv Radiol 2003;14:697-710.

85. Kornbau C, Lee K, Hughes G, et al. Central line complications. Int J Crit Illn Inj Sci 2015;5:170.

86. Arabi M, Almutairi A, Alangari A, et al. Endovascular management of arterial injuries related to venous access: A retrospective review of 10-year single-center experience. Arab J Interv Radiol 2018;2:8.

87. Bountouris I, Kritikou G, Degermetzoglou N, et al. A Review of Percutaneous Transluminal Angioplasty in Hemodialysis Fistula. Int J Vasc Med 2018;2018:1420136.

88. Vascular Access Work Group. Clinical Practice Guidelines for Vascular Access. Am J Kidney Dis 2006;48:S248-73.

89. Turmel-Rodrigues L, Pengloan J, Bourquelot P. Interventional Radiology in Hemodialysis Fistulae and Grafts: A Multidisciplinary Approach. Cardiovasc Intervent Radiol 2002;25:3-16.
90. Bountouris I, Kristmundsson T, Dias N, et al. Is Repeat PTA of a Failing Hemodialysis Fistula Durable? Int J Vasc Med 2014;2014:369687.

91. Miquelin DG, Reis L, da Silva A, et al. Percutaneous transluminal angioplasty in the treatment of stenosis of arteriovenous fistulae for hemodialysis. Int Arch Med 2008;1:16.

92. Friedman T, Lopez EE, Quencer KB. Complications in Percutaneous Dialysis Interventions: How to Avoid Them, and How to Treat Them When They do Occur. Tech Vasc Interv Radiol 2017;20:58-64.

93. Kornfield ZN, Kwak A, Soulen MC, et al. Incidence and Management of Percutaneous Transluminal Angioplastyinduced Venous Rupture in the "Fistula First" Era. J Vasc Interv Radiol 2009;20:744-51.

94. Bittl JA. Venous rupture during percutaneous treatment of hemodialysis fistulas and grafts. Catheter Cardiovasc Interv 2009;74:1097-101.

95. Al Zahrani Y, Peck D. Median sacral artery injury following a bone marrow biopsy successfully treated with selective trans-arterial embolization: a case report. J Med Case Rep 2016;10:42.

96. Arellano-Rodrigo E, Real MI, Muntaola A, et al. Successful treatment by selective arterial embolization of severe retroperitoneal hemorrhage secondary to bone marrow biopsy in post-polycythemic myelofibrosis. Ann Hematol 2004;83:67-70.

97. Luoni M, Croci E, De Paoli A, et al. Retroperitoneal hemorrhage following bone marrow biopsy. Haematologica 1994;79:70-2.

98. Berber I, Erkurt MA, Kuku I, et al. An Unexpected Complication of Bone Marrow Aspiration and Trephine Biopsy: Arteriovenous Fistula. Med Princ Pract 2014;23:380-3.

99. Chamisa I. Fatal vascular retroperitoneal injury following bone marrow biopsy. S Afr Med J 2007;97:246.

100. Sullivan CM, Regi JM. Pseudoaneurysm of the superior gluteal artery following bone marrow biopsy. Br J Haematol 2013;161:289-91.

101. Neesse A, Kalinowski M, Walthers EM, et al. Clinical management of massive retroperitoneal hemorrhage after bone marrow biopsy. Leuk Lymphoma 2009;50:475-7.

Cite this article as: Smith TA, Gage D, Quencer KB Narrative review of vascular iatrogenic trauma and endovascular treatment. Ann Transl Med 2021;9(14):1199. doi: 10.21037/ atm-20-4332 